Universidad de Lima

Escuela de Posgrado

Maestría en Tributación y Política Fiscal

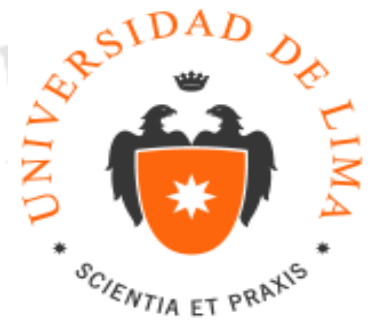

\title{
LA INDEMNIZACIÓN JUSTIPRECIADA RECIBIDA POR UNA EXPROPIACIÓN Y SU AFECTACIÓN AL IMPUESTO A LA RENTA
}

Trabajo de Investigación para optar el Grado Académico de Maestro en Tributación y Política Fiscal.

Carmen Asunción Núñez Ju.

Código 20132483

\author{
Lima-Perú
}

Marzo de 2016 


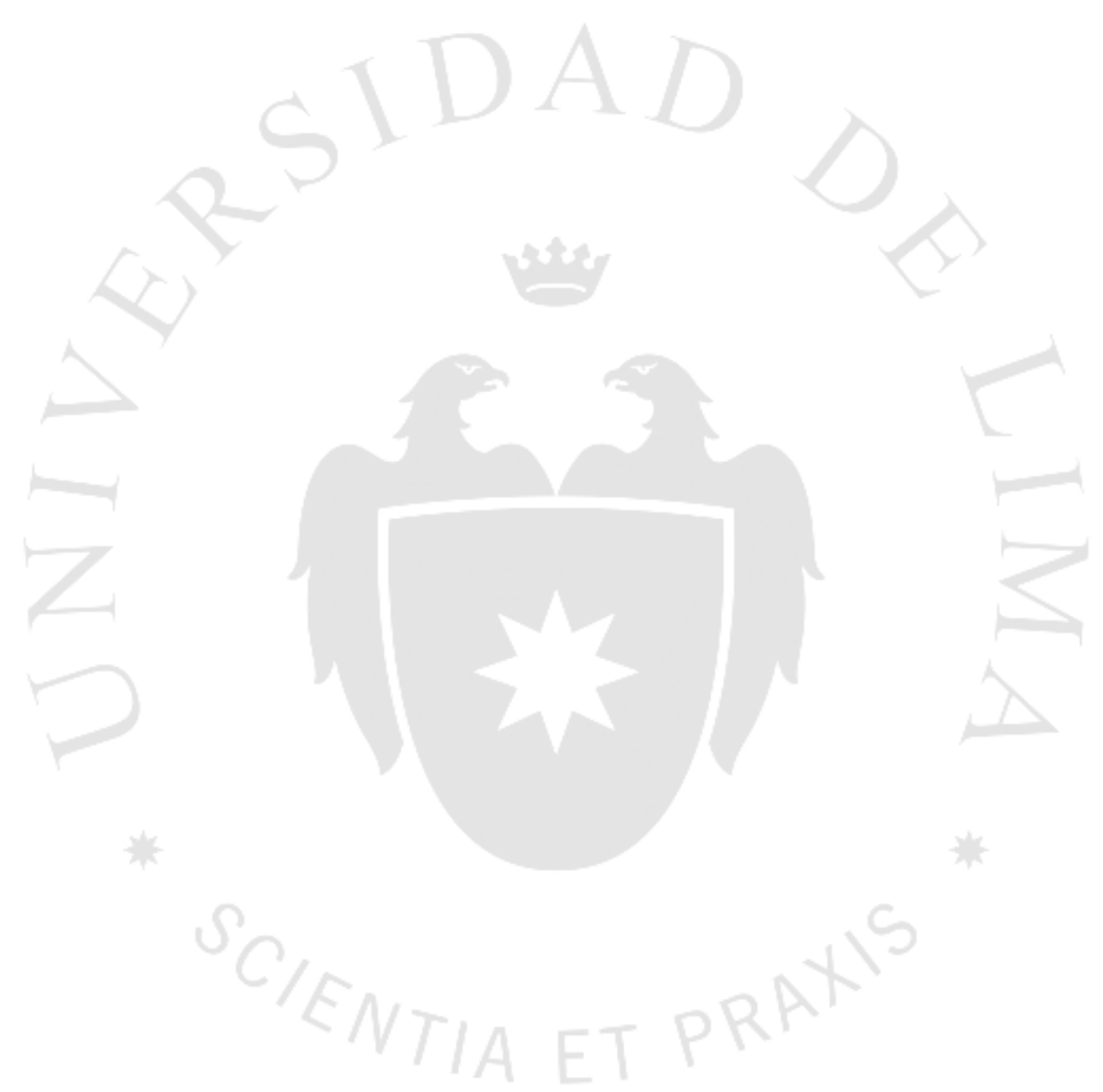




\section{LA INDEMNIZACIÓN JUSTIPRECIADA RECIBIDA POR UNA EXPROPIACIÓN Y SU AFECTACIÓN AL IMPUESTO A LA RENTA}




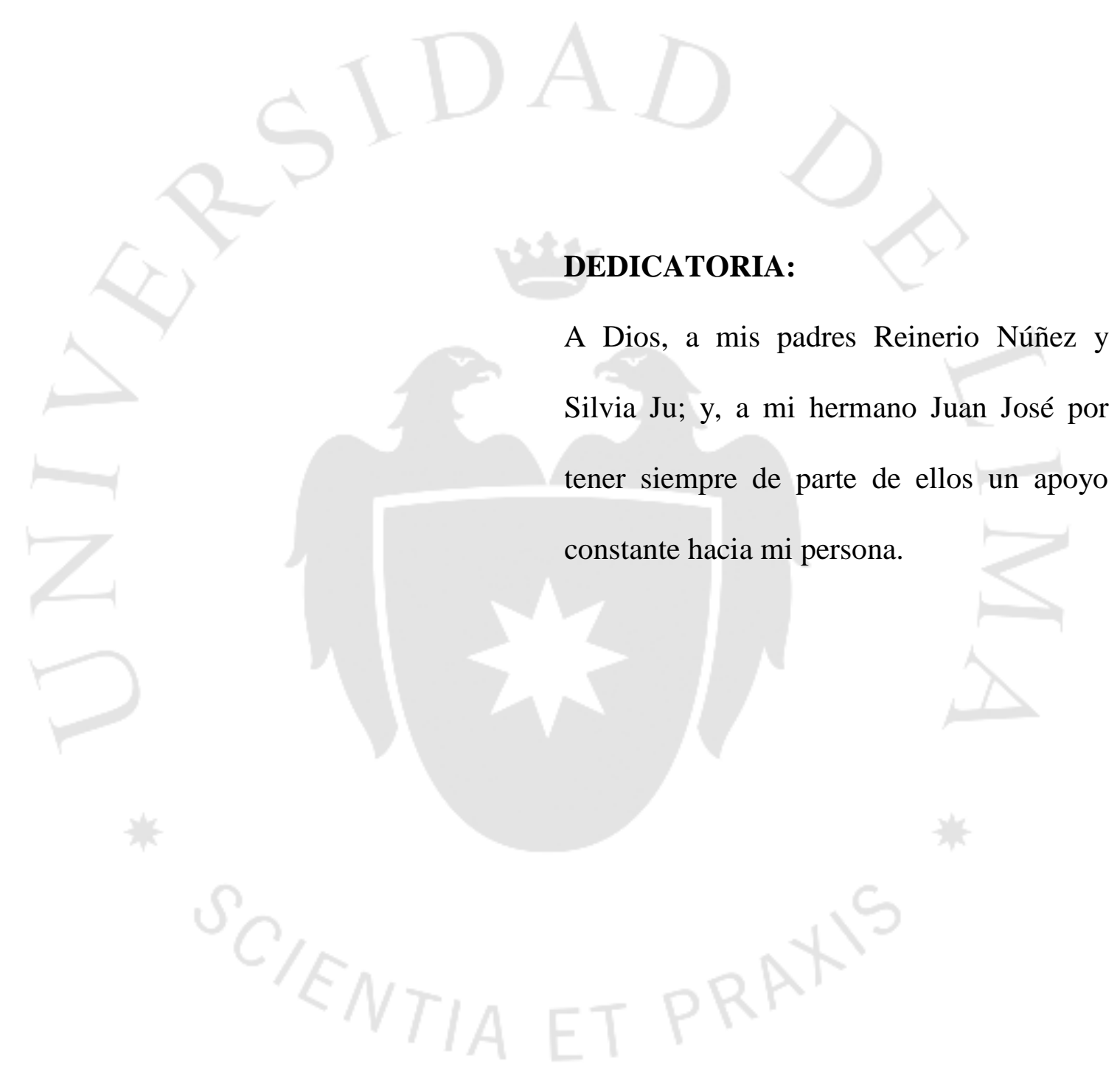




\section{TABLA DE CONTENIDOS}

INTRODUCCIÓN 1

CAPÍTULO I: EL CONCEPTO DE “RENTA" EN LA LEY DEL IMPUESTO A LA RENTA Y LAS DIVERSAS TEORÍAS ADOPTADAS POR LA

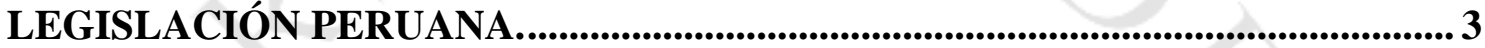

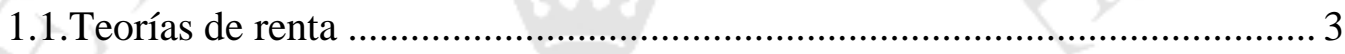

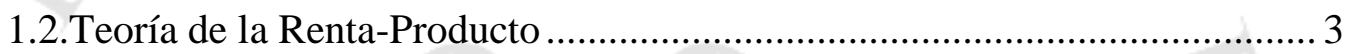

1.3. Teoría del Flujo de Riqueza............................................................. 4

1.4.Teoría del Consumo más Incremento Patrimonial .................................... 6

1.5.El concepto de "renta" en relación a la renta no empresarial y empresarial . 8

1.5.1.El concepto de renta aplicado a los contribuyentes perceptores de renta no

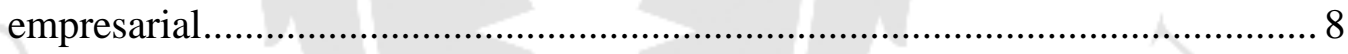

1.5.2.El concepto de renta aplicado a los contribuyentes perceptores de renta

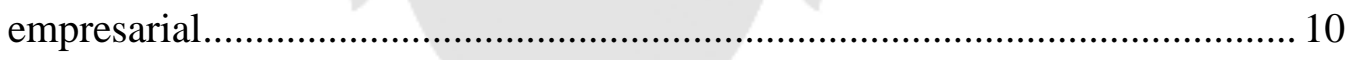

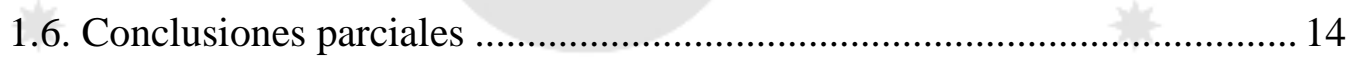

CAPÍTULO II: LA INDEMNIZACIÓN JUSTIPRECIADA Y SU AFECTACIÓN

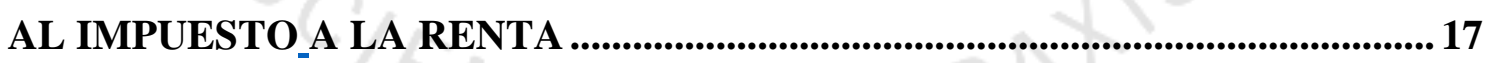

2.1.El proceso de expropiación y su regulación en el Perú .............................. 17

2.2.Argumentos que sustentan el que se grave o no, con el impuesto a la renta, la indemnización justipreciada en un procedimiento de expropiación............... 20

2.2.1.Argumentos que sustentan su gravamen con el Impuesto a la Renta....... 23

2.2.2.Argumentos que sustentan su no gravamen con el Impuesto a la Renta.. 25 
2.3.Posiciones doctrinarias en relación a la afectación de la indemnización justipreciada con el impuesto a la renta.

2.3.1.Posición del Tribunal Constitucional 27

2.3.2.Posición de la Administración Tributaria 30

2.3.3.Posición del Congreso de la República 31

2.3.4.Posición de diversos Juristas 33

2.3.5.Nuestra Posición 34

2.4.Conclusiones parciales 36

CONCLUSIONES 39

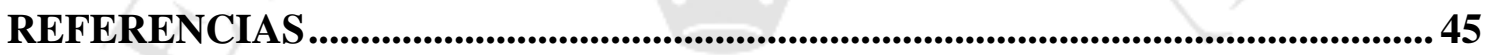

BIBLIOGRAFÍA 49 


\section{INTRODUCCIÓN}

Entre los derechos fundamentales garantizados por la actual Constitución Política del Perú (1993) se encuentra regulado el derecho de propiedad, sosteniéndose que a nadie se le puede privar de manera arbitraria de algo que le pertenece, siendo la única excepción la expropiación.

Esta privación de la propiedad, por causas de seguridad nacional o necesidad pública, conocida como 'expropiación', se encuentra regulada en el Perú, actualmente, por el Decreto Legislativo $\mathrm{N}^{\circ} 1192$, denominado, Decreto Legislativo que aprueba la Ley Marco de Adquisición y Expropiación de inmuebles, transferencia de inmuebles de propiedad del Estado, liberación de interferencias y dicta otras medidas para la ejecución de obras de infraestructura (2015); la cual expresa, que se conoce como expropiación a

La transferencia forzosa del derecho de propiedad privada, sustentada en causas de seguridad nacional o necesidad pública, autorizada únicamente por ley expresa del Congreso de la República a favor del Estado, a iniciativa del Gobierno Nacional, Gobiernos Regionales o Gobiernos Locales y previo pago en efectivo de la indemnización justipreciada que incluya compensación por el eventual perjuicio.

Es esta la base sobre la cual se planteará la cuestión de si el pago que recibe el particular (persona natural o persona jurídica) por parte del Estado, a raíz de la transferencia forzosa de su bien inmueble, se encontraría regulado con el Impuesto a la Renta.

Dicha cuestión implicará analizar el artículo $5^{\circ}$ del Texto Único Ordenado de la Ley del Impuesto a la Renta (2004), en adelante TUO de la LIR, el cual indica que se entiende por enajenación, entre otros supuestos, a la expropiación.

Se planteará la cuestión de si la indemnización justipreciada o justiprecio, a raíz de dicha expropiación, debería estar gravada con el Impuesto a la Renta; puesto que por un lado, se argumenta, que no se puede equiparar la recepción de dicho justiprecio, con el pago por la transferencia voluntaria de un bien, como la compraventa; puesto que, con la expropiación solo se estaría buscando un equilibrio económico, no dando índices de capacidad contributiva. 
Por otro lado, existen argumentos que contradicen el párrafo anterior, indicando que sí debería gravarse con el Impuesto a la Renta, sosteniendo que sí se da una ganancia, la cual provendría del mayor valor recibido por el bien, respecto a su costo de adquisición, es decir, lo que se gravaría sería la diferencia, lo cual sería considerado como una ganancia de capital.

El presente trabajo comprenderá dos capítulos. El primer capítulo de carácter general, el cual es trascendental para el posterior capítulo, abarcará el ámbito de aplicación del Impuesto a la Renta, las teorías más difundidas de renta. Asimismo, el concepto de renta enfocado tanto para rentas no empresariales como empresariales, siendo que en ésta última, se enfatizará el penúltimo párrafo del artículo $3^{\circ}$ del TUO de la LIR.

El segundo capítulo, de carácter más definido, tratará cuestiones más específicas, empezando por qué es lo que se entiende por expropiación y su regulación en el Perú; posteriormente, se tratará de la indemnización justipreciada o justiprecio y su posible afectación o no al Impuesto a la Renta, tomándose en cuenta argumentos a favor y en contra de ello.

Es de resaltar que para ello se han recogido diversas fuentes como la comentada Sentencia del Tribunal Constitucional del Perú, en adelante Sentencia del Tribunal Constitucional o Sentencia del TC, N 00319-2013-PA/TC, en la cual, se solicitaba la inaplicación del artículo $5^{\circ}$ del TUO de la LIR; asimismo, los Informes realizados por la Superintendencia Nacional de Aduanas y de Administración Tributaria, en adelante SUNAT, en materia de expropiación; Proyectos de Ley realizados por las distintas Comisiones en el Congreso de la República, las cuales tratan esta problemática de si la indemnización justipreciada o justiprecio estaría afecto o no al Impuesto a la Renta; así como, la opinión de diversos juristas, finalizando con nuestra posición sobre el problema planteado.

Asimismo, es importante este tema, puesto que el 23 de agosto de 2015, se publicó en el diario "El Peruano" dicho Decreto Legislativo $N^{\circ} 1192$, que aprueba la Ley Marco de Adquisición y Expropiación de Inmuebles, lo cual consiste en un nuevo régimen jurídico aplicable a dichos procesos para la ejecución de obras de infraestructura de interés nacional, con lo cual, se busca se busca unificar en un solo marco legal, las diversas normas que regulan, especialmente, el proceso de 
expropiación, con la finalidad que dichos procesos se vuelvan más expeditivos y agilizar las inversiones tanto públicas como privadas.

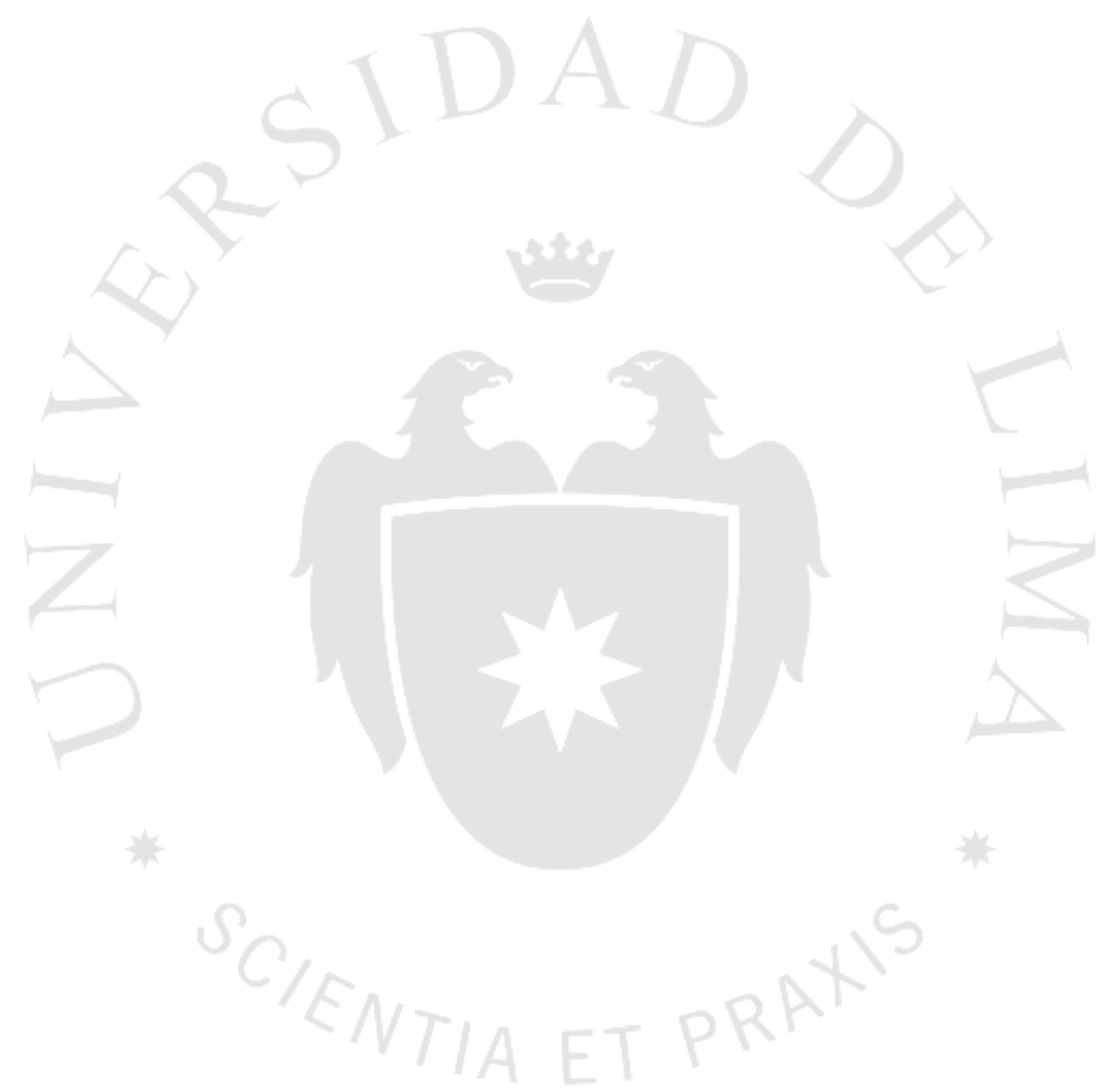




\section{CAPÍTULO I: EL CONCEPTO DE "RENTA" EN LA LEY DEL IMPUESTO A LA RENTA Y LAS DIVERSAS TEORÍAS ADOPTADAS POR LA LEGISLACIÓN PERUANA.}

En el presente capítulo nos centraremos en el concepto de "renta". Como veremos este concepto es importante para definir nuestro objeto de estudio. Posteriormente, entraremos a definir si existe o no una renta cuando se produce un proceso de expropiación.

A continuación, se hará una revisión de las teorías más difundidas de renta que desarrollan este concepto; así como, de qué manera son tratadas en el TUO de la LIR (Decreto Supremo N 179-2004-EF).

\subsection{Teorías de renta}

En la doctrina, se recogen tres teorías ampliamente difundidas. El concepto de "renta" dependerá de la teoría que se adopte para analizar el caso concreto. Se tomará para ello, principalmente, lo indicado por autores como el Dr. Juan Roque García Mullín; así como, de destacados autores nacionales e internacionales.

\subsection{Teoría de la Renta-Producto}

Para esta teoría, denominada también "teoría de la fuente", constituirá renta el producto que se da de manera periódica, que derive de una fuente durable y que ésta se encuentre en estado de explotación. La renta que se genera debe ser un producto separable de la fuente que lo produce, puesto que si no es así, se agotaría en sí misma, y no estaría, la fuente, en condiciones de seguir produciendo renta.

Solo son categorizables como rentas, los enriquecimientos que llenen estos requisitos:

a) Deben ser un producto, es decir, una riqueza nueva distinta y separable de la fuente que lo produce. Por ello, no es renta, en esta concepción, el mayor valor que experimenta un bien, ni el crecimiento operado en un bosque, etc. 
b) Que provengan de una fuente durable, en el sentido de que sobreviva a la producción de la renta, manteniendo capacidad para repetir en el futuro ese acto. Lo importante del concepto, radica en que excluye la consideración como renta de las ganancias de capital, pues en ellas, la fuente se agota (para la persona) en el momento en que la ganancia se realiza.

c) Que la renta debe de ser periódica, como consecuencia del carácter durable de la fuente, y vinculado a él, se afirma la necesaria periodicidad de la renta. No es necesario que la periodicidad se concrete en los hechos (es decir, que realmente se repita la renta), sino que basta con que sea posible.

d) La fuente debe ser puesta en explotación. Es necesario que la fuente haya sido habilitada racionalmente para ello, o sea afectada a destinos productores de renta.

(García Mullín, 1978, pp. 21-22)

En la LIR, esta teoría se encuentra regulada en el artículo $1^{\circ}$, literal a), donde se indica de manera expresa: "El Impuesto a la Renta grava: a) Las rentas que provengan del capital, del trabajo y de la aplicación conjunta de ambos factores, entendiéndose como tales aquellas que provengan de una fuente durable y susceptible de generar ingresos periódicos."

Esta teoría es considerada restringida, pues abarca solo las rentas que provengan de una fuente durable y en estado de explotación; así como, que dicha renta sea periódica. Como sostiene Bravo Cucci (2005), esta teoría tiene su eje central en el origen de la renta, es decir, que provenga de una fuente productora; por lo que no calificarían otros ingresos como las ganancias de capital, ni enriquecimientos distintos a aquellos que provengan de la explotación de una fuente. (p. 41)

\subsection{Teoría del Flujo de Riqueza}

Esta teoría abarca la totalidad de ingresos que provienen de terceros, es decir el total del flujo de riqueza que desde los terceros fluye hacia el contribuyente en un periodo de tiempo dado.

Se caracteriza por ser una teoría más amplia, puesto que no solo implicaría como renta la que provenga de una fuente durable y en estado de explotación; sino que abarcaría otros ingresos. 
Este criterio engloba todas las rentas categorizables como renta producto, pero al no exigir que provenga de una fuente productora durable, ni importar su periodicidad, abarca una serie más de ingresos, que seguidamente se indican:

1. Las Ganancias de Capital Realizadas. Se consideran tales, las originadas en la realización de bienes patrimoniales, en tanto la realización de esos bienes no sea el objeto de una actividad lucrativa habitual.

2. Los Ingresos por actividades accidentales. Son ingresos originados por una habilitación transitoria y eventual de una fuente productora, o sea que provienen de actos accidentales que no implican una organización de actividades con el mismo fin.

3. Los Ingresos Eventuales. Son ingresos cuya producción depende de un factor aleatorio, ajeno a la voluntad de quien lo obtiene, tales como los premios de lotería y los juegos de azar. No hay periodicidad, ni habilitación racional de fuente, de modo que no podrían caber en el concepto de renta producto.

4. Ingresos a Título Gratuito. Comprende tanto a las transmisiones por acto entre vivos (regalos, donaciones), como las por causa de muerte (legados y herencias).

(García Mullín, 1978, pp. 23-24)

García Mullín (1978), en referencia a esta teoría, señaló que se considera como una

(...) condición suficiente y a la vez necesaria para configurar la renta, el hecho de tratarse de enriquecimientos que han fluido desde terceros hacia el contribuyente, independientemente de que sean producto o no de fuente alguna... [Enfatizando], que es necesario que se haya producido una operación con terceros. (p. 24).

En la legislación peruana no existe un artículo que consagre de manera general todos los alcances de la teoría del flujo de riqueza, por tanto, al momento de analizarlas, se revisará más de un artículo de la LIR. En ese sentido, se precisa que "no existe un artículo de la LIR que consagre de manera general todos los alcances de la teoría flujo de riqueza...por lo que la ley peruana tiene que proceder con la descripción de cada de estos casos por separado" (Ruiz de Castilla, 2010, párr. 10).

En el mismo sentido, Fernández Cartagena (2004) señala que es una teoría que incluye en el concepto de renta otros ingresos, además de los que califican como renta producto. Enunciando a las ganancias de capital por ejemplo, las cuales no se podrían incluir en la teoría de renta producto, pues la fuente productora sería el bien vendido, que se agota o desaparece al producirse la enajenación, con la producción de la 
ganancia. Aparte de las ganancias de capital, también se consideraría, como lo señaló anteriormente García Mullín, a los ingresos eventuales e ingresos a título gratuito (p. 3).

El artículo $1^{\circ}$, incisos b) y c) de la LIR, tratan sobre esta teoría, según lo indicado por la doctrina, los cuales expresan: "El Impuesto a la Renta grava:

b) Las ganancias de capital

c) Otros ingresos que provengan de terceros, establecidos por esta Ley".

Es de precisar, que el último párrafo del artículo $2^{\circ}$ de la LIR señala, que no constituye ganancia de capital efectuada por una persona natural (que no genere rentas de tercera categoría), los inmuebles ocupados como casa habitación de la enajenación. Al expresar esto, como señala Cartagena (2004), “la excepción... sería más bien una ratificación del concepto mismo de ganancia de capital, según el cual no existe el gravamen cuando los bienes han sido adquiridos sin ánimo de transferirlos" (p.10).

La Superintendencia Nacional de Aduanas y de Administración Tributaria, en adelante SUNAT o la Administración Tributaria, enfatiza que, por ejemplo, en relación a una empresa domiciliada en el país, a la que se le han efectuado en sus cuentas bancarias en el Perú, depósitos de dinero en efectivo, respecto de los cuales se desconoce su origen; indica que dichos abonos no podrían encontrarse gravados con el Impuesto a la Renta bajo la teoría de renta-producto, puesto que no provienen de una fuente durable y susceptible de generar ingresos periódicos. Asimismo, tampoco bajo la teoría del flujo de riqueza, en tanto dichos abonos no sean el resultado de relaciones que la empresa (que los recibe) haya entablado en el devenir de su actividad con otros particulares, en la que los intervinientes participan en igualdad de condiciones y consienten el nacimiento de obligaciones (Informe $\mathrm{N}^{\circ}$ 0146-2015-SUNAT/5D0000, p. $4)$.

Con esta opinión sentada por la Administración Tributaria, basado en el penúltimo párrafo del artículo $3^{\circ}$ de la LIR; así como, en el artículo $1^{\circ}$ del Reglamento de la Ley del Impuesto a la Renta (Decreto Supremo $N^{\circ}$ 122-94-EF), en adelante RLIR, define, en relación a las personas jurídicas, qué ingresos se encontrarían gravados con el Impuesto a la Renta bajo la teoría del flujo de riqueza.

\subsection{Teoría del Consumo más Incremento Patrimonial}


Para esta teoría, la renta se define como el total del incremento del patrimonio que tenga el sujeto pasivo, es decir, la suma de los consumos más el incremento del patrimonio al final de un periodo determinado. En esta teoría se analizan las variaciones patrimoniales y los consumos realizados en dicho periodo.

Es una teoría más extensa que las dos anteriores mencionadas, puesto que abarca, además de lo comprendido por la teoría de renta producto y por la del flujo de riqueza, cualquier otro incremento que se pueda dar en el patrimonio.

Acerca de esta teoría, se manifiesta:

En este criterio el individuo es el gran protagonista; las satisfacciones de que dispone, a lo largo de un periodo, son el test último de su capacidad contributiva fiscal... La renta, se dice, interesa como índice de capacidad contributiva del individuo, de su aptitud real o potencial para satisfacer necesidades, de su "poder económico discrecional"; si ello es así, para medirla, no hay que recurrir a su origen (fuente o flujo), sino a su constatación a nivel personal a lo largo de un periodo. Analizada bajo ese ángulo, ella se plasma en dos grandes rubros: las variaciones patrimoniales, y los consumos.

1. Las Variaciones Patrimoniales: se considera como renta los cambios o variaciones de valor del patrimonio del individuo, operados entre el comienzo y el fin de un determinado periodo.

2. Los Consumos: el consumo de una persona implica el empleo de bienes y servicios en la satisfacción de necesidades. (García Mullín, 1978, p.25)

La denominada también "teoría del balance" cubre estas dos acepciones mencionadas. Contraponiéndose a la teoría de la fuente (conocida como también teoría de rentaproducto), la teoría del balance considera todo enriquecimiento o todo aumento de valor, incluso accidental, como una renta imponible.

La teoría del consumo más incremento patrimonial se encuentra regulado en el artículo $1^{\circ}$, inciso d) de la LIR, el cual señala que el Impuesto a la Renta grava "las rentas imputadas, incluyendo las de goce o disfrute, establecidas por esta Ley".

La norma hace referencia a las rentas que se obtengan por el hecho de haber “disfrutado" el bien, como pueden ser las rentas presuntas o las rentas fictas. Un ejemplo de ello, es cuando la persona natural cede el uso de un predio a título gratuito regulado en el artículo $23^{\circ}$ de la LIR. 


\subsection{El concepto de "renta" en relación a la renta no empresarial y empresarial}

Tomando en cuenta las teorías de renta mencionadas en el acápite anterior, se relacionará el concepto de renta vinculándolo con el aspecto subjetivo (perceptores de renta no empresarial y renta empresarial).

\subsubsection{El concepto de renta aplicado a los contribuyentes perceptores de renta no empresarial}

Las teorías de renta, en relación con las rentas no empresariales, se aplican para las actividades que desarrollan las personas naturales en relación con sus rentas pasivas y activas y que, valga la redundancia, no desarrollen actividad empresarial. Por ejemplo, el caso de una empresa unipersonal, es decir, una persona natural con negocio, ya se consideraría como una renta empresarial.

Vinculando a los perceptores de renta no empresarial con la teoría de rentaproducto $\mathrm{y}$, teniéndose en cuenta, que ésta grava aquellas rentas que provengan de una fuente durable, que dicho renta o ingreso sea periódico y que provenga de una fuente durable en estado de explotación; se podría sostener que las rentas obtenidas por las personas naturales, en base a esta teoría, se considerarían como rentas que tienen carácter empresarial, es decir, la renta que resulta del capital más trabajo.

En relación con la teoría del flujo de riqueza se considera renta a todo ingreso que provenga de operaciones con terceros. Es decir, en el caso de las personas naturales, se incluye, aparte de las rentas que provengan de una fuente durable y en estado de explotación (que como dijimos en el párrafo anterior, se vincularía más con rentas empresariales); otros ingresos, como las ganancias de capital, ingresos eventuales y otros ingresos que provengan de terceros.

Según Zegarra y Zuzunaga (2004), "la doctrina ha ubicado a las ganancias de capital como renta gravable dentro de los criterios del "flujo de riqueza" (cuando dicha ganancia se realiza a través de la enajenación del bien de capital)" (p. 7).

En el mismo sentido, García Mullín (1978) enfatiza que:

En el criterio del flujo de riqueza [cursivas añadidas], las simples valorizaciones no resultarán alcanzadas, puesto que nada nuevo ha llegado desde terceros al patrimonio del contribuyente. En cambio quedarían comprendidas todas las ganancias de capital realizadas, las que deberán sumarse a las rentas comunes del año. (p. 80) 
Para el caso de las personas naturales, existe una excepción expresada en el último párrafo del artículo $2^{\circ}$ de la LIR, donde se indica que no constituye ganancia de capital, el resultado de la enajenación de inmuebles ocupados como casa habitación del enajenante $\mathrm{y}$, de bienes muebles, distintos a los valores mobiliarios señalados en el artículo 2, inciso a) de dicha LIR. .

Para la persona natural, en el caso de inmuebles, para que éstos no tengan la condición de ganancias de capital, tienen que cumplir con los requisitos para ser casa habitación, siendo éstos, el que se deba mantener en propiedad del bien inmueble al menos dos años y que no esté destinado de manera exclusiva al comercio, industria, oficina, almacén, cochera o similares, como lo señala el primer párrafo del artículo 1-A del RLIR.

Asimismo, es de precisar, que el primer párrafo del artículo $4^{\circ}$ de la LIR indica que existe habitualidad en la enajenación de bienes inmuebles efectuados por una persona natural, a partir de la tercera enajenación. A su vez, el segundo párrafo del inciso d) del artículo $28^{\circ}$ de la LIR indica, con relación a dicho artículo $4^{\circ}$, que constituye renta de tercera categoría la que se origina a partir de la tercera enajenación. Con dichas normas mencionadas, la enajenación de inmuebles ya no se encuadraría en la teoría de flujo de riqueza; sino que, se encuadraría en la teoría de renta producto, infiriéndose de que en cierto modo hay un negocio inmobiliario.

El Informe $N^{\circ}$ 033-2014-SUNAT/5D0000 hace precisión de ello:

En el caso que una persona natural, propietaria de un terreno, venda en diferentes oportunidades parte de su derecho de propiedad sobre éste a diversos compradores dentro del mismo ejercicio gravable, se presume habitualidad a partir de la tercera enajenación, inclusive, de conformidad con lo establecido por los artículos $2^{\circ}$ y $4^{\circ}$ de la Ley del Impuesto a la Renta (p. 3).

También es de aplicación, para las personas naturales, la teoría del consumo más incremento patrimonial. El TUO de la LIR, como se dijo en el subcapítulo anterior, lo regula en el artículo $1^{\circ}$, literal d); se hace referencia a ello, al señalarse, que el Impuesto a la Renta recaerá sobre las rentas imputadas, incluyendo las de goce o disfrute. Por tanto, se incluyen manifestaciones de riqueza que no implican una transacción efectivamente realizada, es decir, se aplican presunciones para esto. Según Ruiz de Castilla (2010), en la LIR, estas presunciones se desarrollan en las rentas fictas o presuntas, por ejemplo, el artículo $23^{\circ}$, inciso d); en el cual se configura una renta ficta 
de predios cuando el propietario haya cedido gratuitamente o a precio no determinado, lo cual se aplica para personas naturales (párr. 15).

La doctrina ha vinculado a esta teoría del consumo más incremento patrimonial con el concepto de ganancia de capital, entendido en una noción amplia; es decir, según García Mullín (1978) dicha ganancia puede ser entendida, por un lado, en un sentido restringido (cuando dichas ganancias se realizan), entendido en el concepto de que se concretan mediante una enajenación; así como, en un sentido amplio, que abarca las ganancias de capital no realizadas, es decir, apreciadas como simples valorizaciones; sosteniendo este autor que dicha teoría abarcaría los dos sentidos (restringido y amplio) de ganancias de capital (p. 80).

Por tanto, las rentas de las personas naturales se vincularán con alguna de las teorías de renta mencionadas, en tanto se encuentre dentro de la situación o circunstancia que sea característica de alguna de ellas. En el TUO de la LIR, como hemos identificado también se encuentran diversas situaciones que identifican a estas teorías.

El tema materia de la tesis se centrará, como se apreciará en el próximo capítulo, en la expropiación y su vinculación con el Impuesto a la Renta. Al tratarse de personas naturales, el TUO de la LIR en el artículo $24^{\circ}$, literal j), considera como rentas de segunda categoría a las ganancias de capital. Dentro de ello, está incorporado, el caso de las ganancias que obtienen las personas naturales que enajenan bienes inmuebles que no están destinados para la venta; caso en el cual, podría encontrarse la expropiación, puesto que en esta figura, como se explicará más adelante, dicha transferencia se da de manera forzosa no siendo producto de un negocio inmobiliario.

\subsubsection{El concepto de renta aplicado a los contribuyentes perceptores de renta empresarial}

En cuanto a las rentas empresariales, generadoras de rentas de tercera categoría, se debe precisar, que generalmente se va a hacer énfasis en que sus rentas provengan de operaciones con terceros.

Este tipo de rentas (tercera categoría) va a provenir de las actividades de tipo empresarial realizadas por las personas naturales; así como, por toda actividad que realicen las personas jurídicas. 
García Mullin (1978), sobre la aplicación del criterio de renta producto para el caso de rentas empresariales, le otorga un carácter de amplitud conceptual, postulando el principio de la empresa como fuente pero:

Siempre manteniéndose dentro del criterio de la renta producto... [Es decir]. Se sostiene que la fuente productora de las rentas no es la aplicación conjunta de capital y trabajo; sino, la empresa que resulta de esa aplicación. Como consecuencia de ello, si la fuente productora durable es la empresa misma, todos los productos que de ella se derivan, en tanto sean riqueza material nueva, constituyen renta producto, sin interesar que se originen en operaciones que formen o no parte de la actividad normal. (p. 32)

En el caso que se cuente con un criterio en el que se considere como beneficios empresariales a todos los aumentos del patrimonio de una determinada empresa, se estará en aplicación de la teoría del balance o del consumo más incremento patrimonial.

El penúltimo párrafo del artículo $3^{\circ}$ de la LIR indica que constituye renta gravada de las empresas, "cualquier ganancia o ingreso derivado de operaciones con terceros". La LIR denomina de este modo la renta gravada de las empresas, basándose en el concepto general de renta bajo la teoría del flujo de riqueza. Al leerse esta frase se podría entender, como señala García Mullín (1978), que la aplicación del criterio del flujo de riqueza, en el caso de empresas, otorga al concepto de renta la misma amplitud, que el principio de la empresa fuente, descrito en el párrafo anterior.

Podría parecer la misma amplitud; no obstante:

Las ganancias de capital, en el concepto de renta producto serían gravadas como un producto más de la fuente; y en el concepto de flujo de riqueza se les podría reconocer como ingresos de distinto tipo, lo cual posibilitaría tratamientos especiales. (García Mullín, 1978, p. 32).

El inciso g) del artículo $1^{\circ}$ del RLIR señala y específica, lo que se debe entender por ganancia o ingreso derivado de operaciones con terceros [cursivas añadidas], refiriéndose, "a la obtenida en el devenir de la actividad de la empresa en sus relaciones con otros particulares, en las que los intervinientes participan en igualdad de condiciones y consienten el nacimiento de obligaciones".

Frente a ello, han existido diversas opiniones, señalando que dicho concepto podría tener un carácter restringido, teniéndose en cuenta que los ingresos que pueda obtener una empresa; podrían no solo provenir de operaciones con otros particulares en igualdad de condiciones; sino también, de una relación con el Estado, por ejemplo. 
Bravo Cucci (2005) señala, como principal argumento, que lo establecido en el RLIR, vulnera el principio de legalidad, al contradecir lo establecido en el TUO de la LIR en su artículo $3^{\circ}$; puesto que quedarían exentos de renta actividades que realiza una empresa en su devenir, pero que lo hace teniendo como contraparte a un sujeto que no se encuentre en igualdad de condiciones, como puede ser el Estado. Asimismo, sostiene, que también se vulneraría el principio de igualdad; puesto que, no se estaría afectando con el Impuesto a la Renta a un sujeto que recibe subsidios en la misma cuantía, como los ingresos por actividades comerciales de un empresario común (p. 45).

Otro argumento que se podría sostener, para que se pueda gravar una operación realizada entre un particular y el Estado, es indicar que el Impuesto a la Renta grava hechos económicos; sin que sea relevante la causa jurídica de éstos (que provenga de una relación entre dos sujetos que no están en igualdad de condiciones). Dicho argumento fue sustentado por la Administración Tributaria, como parte demandada, frente al recurso de agravio constitucional interpuesto por un contribuyente ante el Tribunal Constitucional en el año 2013 y que más adelante se detallará.

Frente a estas diversas opiniones, partimos del hecho que lo expresado en las normas no tiene un carácter restringido; sino, que podría implicar el respeto al bien común. Cuando no se está en una relación de igualdad de condiciones, como la que puede darse entre el Estado y el particular se debe, frecuentemente, a una causa que implica el que se hayan desplegado mandatos legales, ya sea para un mejor desempeño del Estado en sus funciones o, también, para otorgarle beneficios al particular que vayan acorde con un Estado Social y Democrático de Derecho.

La Administración Tributaria ha emitido diversos Informes acerca de si estaría gravada o no, la relación entre un Estado y un particular. En la Resolución del Tribunal Fiscal, en adelante RTF, $N^{\circ}$ 616-4-1999, la cual es Jurisprudencia de Observancia Obligatoria, se refirió a esto, sosteniendo que:

Las obligaciones tributarias y los beneficios otorgados respecto de las mismas, nacen por imperio de la Ley, independientemente del deudor tributario, lo que no sucede en el caso de obligaciones entre particulares, siendo en consecuencia una relación entre Estado y particular. (p. 1)

La RTF N 01930-5-2010, se pronunció acerca de esta relación, pero en el caso de una donación, indicando que una donación proveniente del Programa Nacional de Agua Potable y Alcantarillado, en adelante PRONAP (entidad del Estado), no se encuentra 
comprendida dentro del concepto de renta bajo la teoría del flujo de riqueza; señalándose, que distinto sería el caso de una donación efectuada por un particular como Southern Peru, al provenir de una operación con un tercero (p.7).

Es de precisar, que en esta Resolución, se dio un voto discrepante en parte, del Vocal Ezeta Carpio sobre dicho criterio, indicando, que la referida transferencia a título gratuito no se efectuó por mandato de dispositivos legales sino en virtud a un convenio celebrado entre el Estado (a través del PRONAP) y la recurrente... debe tenerse presente que al tratarse de ingresos obtenidos en virtud de un acuerdo de voluntades entre el Estado y un particular, en el que ambas partes actúan en igualdad de condiciones, se está ante ingresos provenientes de operaciones con terceros (p. 16).

Se enfatiza, en base a ponencias que tuvieron como tema de vinculación el penúltimo párrafo del artículo $3^{\circ}$ de la LIR y, el artículo $1^{\circ}$, inciso g) del RLIR, que:

Existe un acuerdo unánime en el sentido que las sumas que el Estado entrega al contribuyente por mandato de la Ley no constituyen renta gravada por no ser operaciones con terceros, ya que no se obtienen por la empresa en sus relaciones con otros particulares. (Medrano Cornejo, 2004, p. 7).

Como refuerzo de esta posición, se señala la RTF $\mathrm{N}^{\circ}$ 00542-1-2007, el cual trata sobre los ingresos obtenidos como producto del acogimiento al régimen aduanero del drawback, indicándose en dicha Resolución que:

Siendo que tales ingresos son recibidos luego de cumplirse con los requisitos establecidos por la norma correspondiente, dicho beneficio nace de un mandato legal y no de la actividad entre particulares (operaciones con terceros), por tanto no se encuentran comprendidos en el concepto de renta recogido en la teoría del flujo de riqueza. (p. 2)

Por tanto, tal beneficio concedido por el Estado, no tendría la naturaleza de renta, puesto que no procede de una operación con un tercero; concluyéndose, que se constituiría en un subsidio estatal.

Los Informes de la Sunat, también son de este parecer, por ejemplo en el Informe $\mathrm{N}^{\circ}$ 064-2006-SUNAT/2B0000, referente, a si los ingresos originados por la aplicación del beneficio del Crédito Fiscal Especial, regulado en la Ley de Amazonía, se encuentran o no gravados con el Impuesto a la Renta; se indicó:

De otro lado, debe tenerse en consideración que los ingresos generados a favor de los contribuyentes al aplicar el beneficio del Crédito Fiscal Especial, no se originan de 
operaciones con particulares en los términos señalados en el inciso g) del artículo $1^{\circ}$ del Reglamento de la Ley del Impuesto a la Renta, sino de un derecho concedido en base al IUS IMPERIUM del Estado, [cursivas añadidas], por lo que el referido ingreso tampoco se ajusta al criterio del flujo de riqueza asumido por nuestra legislación.

En consecuencia los ingresos originados por la aplicación del beneficio del Crédito Fiscal Especial regulado en la Ley de la Amazonía no se encuentran gravados con el Impuesto a la Renta. (p. 3)

No obstante, es de precisar, que no necesariamente una relación entre el Estado y el particular (que genere renta empresarial), va a conllevar que no se encuentre gravada dicha operación entre las partes. Es necesario, evaluar el caso concreto en el que se lleva a cabo dicha relación, puesto que si bien el Estado no se encuentra en igualdad de condiciones con el particular, pueden darse situaciones en el que sí lo estén.

Por ejemplo, el que se lleven a cabo convenios entre las partes, como las transferencias que realice a título gratuito el Estado mediante un acto de liberalidad, sin efectuarse por mandato de dispositivo legales, sería un claro ejemplo en donde el Estado actúa en igualdad de condiciones con el particular.

\subsection{Conclusiones parciales}

- De las tres teorías ampliamente difundidas de renta: la teoría de la rentaproducto, la teoría del flujo de riqueza y la teoría del consumo más incremento patrimonial; la que más se relaciona con la expresión “ingresos provenientes de operaciones con terceros" es la teoría del flujo de riqueza.

- La teoría del flujo de riqueza incluye la totalidad de los ingresos provenientes de terceros. Dentro de dicho ingresos, se encuentran las ganancias de capital. En el TUO de la LIR, se hace referencia a qué es lo que no constituiría ganancia de capital, para el caso de personas naturales que no generan rentas de tercera categoría. Dentro de estas excepciones, se encuentran los inmuebles ocupados como casa habitación del enajenante, los valores mobiliarios que no se encuentran en el artículo 2, inciso a) del TUO de la LIR; así como, los inmuebles que fueron adquiridos antes del 01 de enero de 2004, según lo señala el numeral 1, de la 35ª Disposición Transitoria y Final del TUO de la LIR.

- Cuando se trata de rentas empresariales, el mismo TUO de la LIR indica que será renta gravada, cualquier ganancia o ingreso derivado de operaciones con 
terceros. El RLIR, en el artículo $1^{\circ}$, inciso g), específica este último concepto, refiriéndose "a lo obtenido en el devenir de la actividad de la empresa en sus relaciones con otros particulares, en la que los intervinientes participan en igualdad de condiciones y consienten el nacimiento de obligaciones". Dicha norma reglamentaría ha recibido cuestionamientos en donde se especifica que podría estarse transgrediendo el principio de legalidad.

- Es muy importante delimitar la expresión "ingreso derivado de operaciones con terceros", analizando el caso concreto y, no solo considerando quiénes son los que realizan la operación (aspecto subjetivo); sino también, qué operación en específico están llevando a cabo las partes.

- Cuando se hace referencia a esta expresión de "ingreso derivado de operaciones con terceros", la cual es desarrollada y especificada por el RLIR, se entiende que se aplica a situaciones en donde existe consentimiento en el nacimiento de las obligaciones entre particulares. Se ha dado una voluntariedad en las partes para llevarlas a cabo.

- Cuando se presentan situaciones como nacimiento de los tributos y/o beneficios otorgados que nazcan por imperio de la ley (Ius Imperium); implicaría la existencia de una relación entre el Estado y el particular, donde la voluntariedad puede verse mermada.

- En una situación en la que no hay igualdad de condiciones, como la que se puede dar entre el Estado y el particular, es frecuente que los beneficios nazcan por un mandato legal (por ejemplo, devolución del capital, como de los intereses, condonaciones que hace el Estado de tributos, etc.); en el sentido, que no hay un acuerdo consentido de las partes para la obtención de dichos posibles beneficios.

- Las resoluciones del Tribunal Fiscal han recalcado lo expresado en el penúltimo párrafo del artículo $3^{\circ}$ del TUO de la LIR. En el caso del régimen aduanero del Drawback, se resalta que el beneficio nace de un mandato legal y no, de un consentimiento entre las partes en igualdad de condiciones. Se concluye que más bien se trata de un subsidio otorgado por el Estado, por lo que, los ingresos por dicho régimen (Drawback), no califican como renta. 
- Si bien en una relación entre el Estado y el particular es frecuente que no se presente una igualdad de condiciones entre dichas partes; podrían darse situaciones en la que éstas sí lo estarían, como el caso de una transferencia a título gratuito que no se haya efectuado por mandato de dispositivos legales.

- El particular podría celebrar convenios con el Estado, en el que éste último actúe en igualdad de condiciones con el particular, lo cual derivaría a que se origine un ingreso derivado de operaciones con terceros que se encontraría gravado con el Impuesto a la Renta, como lo señalado en la RTF N 01930-5-2010.

- Consideramos que lo desarrollado en el Reglamento de la LIR no tiene carácter restrictivo, en el sentido de que al darse mediante dispositivos legales, el Estado debiera tener motivos de por qué se han publicado, cuál ha sido la intención al hacerlo, ya sea en aras del bien común, por un Estado Social y Democrático de Derecho. Por ello, es preciso el análisis concreto de la relación, ver tanto el aspecto sustancial u objetivo de la operación, como el aspecto subjetivo de la misma. 


\title{
CAPÍTULO II: LA INDEMNIZACIÓN JUSTIPRECIADA Y SU AFECTACIÓN AL IMPUESTO
}

\author{
A LA RENTA
}

\subsection{El proceso de expropiación y su regulación en el Perú}

El proceso de expropiación en el Perú se encuentra regulado, actualmente, por la Ley Marco de Adquisición y Expropiación de inmuebles, transferencia de inmuebles de propiedad del Estado, liberación de interferencias y dicta otras medidas para la ejecución de obras de infraestructura (Decreto Legislativo $\left.\mathrm{N}^{\circ} 1192,2015\right)^{1}$.

La expropiación se encuentra relacionada al derecho de propiedad, regulado en el artículo $2^{\circ}$, inciso 16, de la actual Constitución Política del Perú (1993). La expropiación, a la que se hace referencia en dicho D.L N ${ }^{\circ} 1192$ (2015), es la referida a la del artículo $70^{\circ}$ de dicha Constitución Política (1993), el artículo $928^{\circ}$ del Código Civil (1984) y los artículos 519 al 532 del Código Procesal Civil (1993).

Como todo derecho fundamental, el derecho de propiedad tiene límites, como el bien común. En el caso del derecho de propiedad, su contenido esencial no puede trastocar dicho bien común, una de estas limitaciones hacia este derecho se manifiesta en la expropiación.

El artículo $70^{\circ}$ de la actual Constitución Política del Perú (1993) señala:

El derecho de propiedad es inviolable. El Estado lo garantiza. Se ejerce en armonía con el bien común y dentro de los límites de ley. A nadie puede privarse de su propiedad sino, exclusivamente, por causa de seguridad nacional o necesidad pública, declarada por ley, y previo pago en efectivo de indemnización justipreciada que incluya compensación por el eventual perjuicio. Hay acción ante el Poder Judicial para contestar el valor de la propiedad que el Estado haya señalado en el procedimiento expropiatorio.

\footnotetext{
${ }^{1}$ Como información adicional, en la Disposición Complementaria Derogatoria de dicho D.L. N ${ }^{\circ} 1192$, se precisa, que se deroga la Ley $N^{\circ} 27117$, denominada Ley General de Expropiaciones; la Ley N ${ }^{\circ} 30025$ (Ley que facilita la adquisición, expropiación y posesión de bienes inmuebles para obras de infraestructura y declara de necesidad pública la adquisición o expropiación de bienes inmuebles afectados para la ejecución de diversas obras de infraestructura y ; los artículos $29^{\circ}$ al $37^{\circ}$ y la Séptima Disposición Complementaria Final de la Ley $\mathrm{N}^{\circ} 30327$, denominada Ley de Promoción de las Inversiones para el Crecimiento Económico y el Desarrollo Sostenible.
} 
Desarrollando este concepto anterior, el artículo $4^{\circ}$, numeral 4, del D.L. $\mathrm{N}^{\circ} 1192$

(2015), en el cual se dan las definiciones se entiende por Expropiación:

Es la transferencia forzosa del derecho de propiedad privada sustentada en causa de seguridad nacional o necesidad pública, autorizada únicamente por ley expresa del Congreso de la República a favor del Estado, a iniciativa del Gobierno Nacional, Gobiernos Regionales o Gobiernos Locales y previo pago en efectivo de la indemnización justipreciada que incluya la compensación por el eventual perjuicio, conforme al artículo $70^{\circ}$ de la Constitución Política del Perú y las reglas establecidas en el presente Decreto Legislativo.

Se han señalado estos artículos de nuestra regulación peruana, puesto que ambos recogen aspectos básicos que definen y estructuran el proceso de expropiación, como son:

a) Que el único beneficiario sea el Estado, no un particular.

b) Solo puede darse por causas excepcionales como la seguridad nacional o necesidad pública.

c) Autorizada únicamente por ley expresa del Congreso.

d) Antes de transferirse la propiedad al Estado, deberá hacerse el pago indemnizatorio (indemnización justipreciada o justiprecio).

e) Con este proceso expropiatorio se puede generar un eventual perjuicio.

En igual sentido, si se revisa la legislación comparada, la expropiación en España regulada en el artículo 33.3 de la Constitución Española (1978); así como, en la Ley de Expropiación Forzosa del 16 de diciembre de 1954 y su respectivo Reglamento, aprobado por Decreto de fecha 26 de abril de 1957; también, toma estos puntos básicos, considerando a la expropiación como a la "privación singular de la propiedad privada, o de derechos o intereses patrimoniales legítimos"; teniéndose en cuenta, que para llevarla a cabo, se deberá hacer por una causa justificada (denominada en España, causa justa o interés social [cursivas añadidas] (García de Enterría, 2006, p. 1116).

García de Enterría (2006) precisa acerca de esto:

En el Derecho español el concepto de "utilidad pública o "interés social" no es un concepto abierto que corresponda a la Administración aplicar a unas u otras operaciones a su arbitrio para concluir la pertinencia de la expropiación; por el contrario, ni por acto singular, ni por vía reglamentaria puede la Administración determinar originariamente qué operación merece o no beneficiarse del instrumento expropiatorio por entenderla de utilidad pública o interés social, sino que ese juicio está reservado en nuestro Derecho a 
la Ley. A la Ley, en efecto, y solo a ella, corresponde en nuestro sistema determinar en exclusiva el tipo de operaciones que han de calificarse de utilidad pública o de interés social. (p. 1143)

Garrido Falla (2006) reitera que:

El Tribunal Constitucional Español ha destacado la doble naturaleza de la expropiación en tanto que técnica destinada, por un lado, a la consecución de los intereses públicos y, por otro, a garantizar intereses económicos privados. $\mathrm{Y}$ así ha señalado que la expropiación forzosa, además de ser un medio indeclinable de que los poderes públicos pueden y deben servirse para el logro de sus fines, constituye al tiempo una garantía constitucional del derecho de propiedad privada, en la medida en que con ella se asegura una justa compensación económica a quienes, por razones de utilidad pública o interés social, se ven privados de sus bienes o derechos de contenido patrimonial. (p. 281)

Analizando estos conceptos sobre el concepto de expropiación y qué es lo que implica se puede deducir que es una limitación que solo se da por razones estrictamente necesarias, siendo quien verifique esas razones el propio Congreso de la República y, si son dables, se autorizará por ley expedida por dicho Congreso.

Con ello, se puede ver la relevancia que tiene la expropiación, puesto que no es autorizada con una aprobación simple o mediante normas emanadas por un Gobierno Municipal o Regional; sino que es necesario que se den razones que impliquen la salvaguarda del interés público o la seguridad del país, puesto que es evaluado por el Gobierno Central, ya que como señala expresamente el D.L. $N^{\circ} 1192$ (2015), la expropiación es autorizada únicamente por ley expresa del Congreso de la República a favor del Estado, a iniciativa del Gobierno Nacional, Gobiernos Regionales o Gobiernos Locales [cursivas añadidas].

En la definición de expropiación, señalada en dicho Decreto, se enfatiza que se dará un previo pago en efectivo de la indemnización justipreciada [cursivas añadidas], el cual, en el proceso de Expropiación es el valor de Tasación, como se indica en el artículo $13^{\circ}$, numeral 4 , de dicha Norma.

Precisamente, para la fijación del valor de Tasación se considerará el valor comercial del inmueble y el valor de perjuicio económico.

En ese sentido, el pago previo que realice el Estado hacia el particular será el valor de Tasación actualizado, es decir el valor que tiene el bien al momento de la 
expropiación; así como, la compensación que se debe dar si en caso hubiera daños y perjuicios para el sujeto pasivo. El legislador al expresar ello, infiere que producto de la expropiación se podría generar un perjuicio al particular, puesto que además de coaccionarlo a que dé su bien propio, sin ánimo de voluntariedad; recibiría una indemnización, que en el peor de los casos podría ser un pago menor de lo que en realidad le costó el bien.

Por tanto, la norma es expresa al indicar que se debe abonar una indemnización por el eventual perjuicio en caso de acreditarse "fehacientemente" el lucro cesante y el daño emergente; conllevando con ello, a que se pueda dar una situación de equilibrio, donde el particular no salga afectado de este proceso.

Gutiérrez (2010) al referirse a esto precisa:

El sentido de la reparación apunta a proteger el derecho de propiedad del afectado, a que no se empobrezca producto de la expropiación y a que en lo posible quede en igual situación económica... El Estado deberá reintegrar al afectado, el valor económico, incluidos los daños y perjuicios, del bien expropiado, no deberá pagar ni más ni menos, pues no se trata de un negocio sino de una reparación. (p. 158)

Asimismo, Dromi (2005) indica: "La indemnización expropiatoria, en nuestro ordenamiento jurídico, debe ser previa y justa... No es un precio, sino el resarcimiento del daño sufrido con motivo del acto expropiatorio. La indemnización debe ser integralmente justa" (p. 213).

La expropiación, al implicar una desposesión del derecho fundamental a la propiedad, ya suma relevancia en su regulación. Se podría adoptar lo sostenido por Dromi, indicándose, que "dos serían los aspectos esenciales de la expropiación, siendo el primero la transferencia del derecho de propiedad del expropiado al expropiante y, como segundo elemento, el nacimiento del derecho a la indemnización a favor del expropiado" (Dromi, 2005, p. 204).

Lo sostenido por Dromi, conjuga elementos esenciales, que son tratados en los artículos mencionados de las normas peruanas que tratan la expropiación, como son, la extinción del derecho de propiedad sobre un bien, el pago de una indemnización previa por razones excepcionales, como la seguridad nacional o necesidad pública.

2.2. Argumentos que sustentan el que se grave o no, con el impuesto a la renta, la indemnización justipreciada en un procedimiento de expropiación 
Actualmente, en el artículo $13^{\circ}$, numeral 2, del D.L. $N^{\circ} 1192$ (2015) se señala lo que hasta agosto del 2015 se regulaba en la Ley que facilita la adquisición, expropiación y posesión de bienes inmuebles para obras de infraestructura y declara de necesidad pública la adquisición o expropiación de bienes inmuebles afectados para la ejecución de diversas obras de infraestructura (Ley $N^{\circ} 30025,2013$ ), en su artículo $5^{\circ}$. Lo que se enfatiza de dichas regulaciones, es que el valor de la tasación para adquirir inmuebles deberá considerar una indemnización por eventual perjuicio causado que comprenda únicamente al daño emergente y lucro cesante. El monto de la indemnización debe considerar, entre otros, el resarcimiento de los gastos tributarios, incluyendo el Impuesto a la Renta.

Para la fijación del valor de la tasación, al leerse lo que comprendería el mismo, se encuentra incluido el valor del perjuicio económico; el cual, tiene diversas consecuencias tributarias. Cuando se expresa que el monto de la indemnización justipreciada deberá considerar, el daño emergente y el lucro cesante, se debe precisar que al momento de gravarse, no se considerará la suma recibida por daño emergente, en base al artículo $3^{\circ}$, inciso a) del TUO de la LIR y el artículo $1^{\circ}$, inciso e) del RLIR.

Es el TUO de la LIR la que indica, de manera expresa, que el daño emergente no estará gravado con el impuesto a la renta y, ello es aceptable, puesto que cómo gravar algo que resulte un daño inmediato al particular, por ejemplo, el despojo coaccionado de su bien.

Por otro lado, lo que sí pudiera estaría gravado sería el lucro cesante, la ganancia que el particular dejaría de percibir como producto de la transferencia forzosa de su bien al Estado. Por ello, cuando se determine el monto por abonar al sujeto expropiado, se debe distinguir ambos conceptos para que no sea monto gravable el que provenga del daño emergente.

No obstante, es de precisar como comentaremos en los párrafos posteriores de este subcapítulo, que estos conceptos varían ya sea se trate de persona natural, sucesión indivisa o sociedad conyugal que optó por tributar como tal, que no genere rentas de tercera categoría; o, de sujetos que sí generan rentas de tercera categoría.

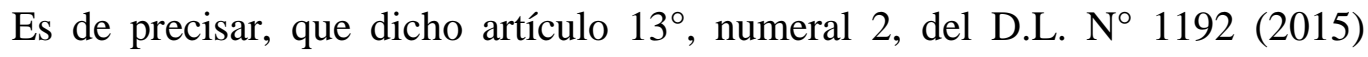
establece lo que se deberá considerar para determinar el valor de tasación, expresando, 
(como se mencionó en los párrafos anteriores) que se incluirá una indemnización por el perjuicio causado [cursivas añadidas]; lo cual, significa, que se pagará por ocasionarse un detrimento al particular, lo que puede resultar contradictorio con lo que continúa de la norma.

Lo que prosigue de la norma señala, que el monto de tasación deberá incluir el resarcimiento de los gastos tributarios, incluyendo el Impuesto a la Renta [cursivas añadidas]; frente a lo cual, se podría entrar en una doble posición, puesto que si bien por un lado, se señala, que para fijar el monto de la tasación para adquirir el bien inmueble, el Estado deberá considerar una indemnización que tome en cuenta el perjuicio causado hacia el particular; por otro lado, parte de lo pagado lo tendría de vuelta el Estado, al pagarse el Impuesto a la Renta.

En la normativa anterior, Ley $\mathrm{N}^{\circ} 30025$, que precisamente regulaba la fijación del valor de la tasación, se indicaba, expresamente, que se incluía "una indemnización por el perjuicio causado"; lo cual, en la actual regulación (D.L $N^{\circ} 1192$ ) se hace referencia que se incluirá una indemnización por el eventual perjuicio causado_[cursivas añadidas].

Se enfatiza esto, porque actualmente la norma vigente es la conjunción de las actualmente derogadas Ley General de Expropiaciones (Ley N 27117, 1999) y, la Ley que facilita la adquisición, expropiación y posesión de bienes inmuebles para obras de infraestructura y declara de necesidad pública la adquisición o expropiación de bienes inmuebles afectados para la ejecución de diversas obras de infraestructura (Ley $\mathrm{N}^{\circ}$ 30025, 2013) mencionada al inicio de este subcapítulo. Es decir, actualmente, se regulan en una sola norma, tanto la adquisición como la expropiación de bienes inmuebles, por lo que al referirse al eventual perjuicio, se infiere que sí lo habría, al darse por medio de la expropiación al ser una transferencia forzosa por parte del sujeto pasivo al Estado.

Es de resaltar, que el Informe $\mathrm{N}^{\circ}$ 0149-2015-SUNAT/5D0000, se pronuncia acerca de estos conceptos señalados en estos párrafos anteriores, indicando, qué conceptos que integran el precio de expropiación de inmueble(s) que percibe el sujeto pasivo, no se encuentran gravados con el Impuesto a la Renta:

a) Tratándose de personas naturales, sucesiones indivisas o sociedades conyugales que optaron por tributar como tales, las indemnizaciones por lucro cesante y daño emergente; así como, el resarcimiento del Impuesto a la Renta. 
b) Tratándose de sujetos perceptores de rentas de tercera categoría, las indemnizaciones por daño emergente y el resarcimiento del Impuesto a la Renta.

(Informe $\mathrm{N}^{\circ}$ 0149-2015-SUNAT/5D0000, 2015, p. 6)

Con dicho Informe de la Administración Tributaria se puede inferir, que tratándose de perceptores de renta de tercera categoría, lo que sí estaría gravado con el Impuesto a la Renta sería el lucro cesante. Asimismo, precisa, que tanto para perceptores, como no perceptores, de renta de tercera categoría lo que sí no estaría gravado sería las indemnizaciones que se confieran por daños emergentes, puesto que como lo recalcamos en los párrafos anteriores no se podría gravar algo que resulte un daño inmediato al sujeto pasivo o particular.

\subsubsection{Argumentos que sustentan su gravamen con el Impuesto a la Renta}

Entre los argumentos que sustentan el gravamen de la indemnización justipreciada con el Impuesto a la Renta, se cuenta con los vertidos por la Administración Tributaria o la SUNAT.

a) La Administración Tributaria tanto en sus Informes, como en sus fundamentos para sustentar frente al Tribunal Constitucional, ha enfatizado que lo que se grava no es la indemnización justipreciada como tal; sino, la posible ganancia que de ésta se pueda derivar.

En ese sentido, considera que lo que se debe gravar debe ser la renta o ganancia que se obtenga, no la propiedad que se tenga sobre el bien. La SUNAT, precisa, que no debe recaer un impuesto a la indemnización justipreciada como tal; sino, a lo resultante de la comparación de dicha indemnización (lo cual como señala la norma, incluye el valor comercial del bien expropiado) en relación a su costo de adquisición.

Se sustenta para ello, en lo señalado en el segundo párrafo del artículo $20^{\circ}$ del TUO de la LIR, el cual indica que "cuando tales ingresos provengan de la enajenación de bienes, la renta bruta estará dada por la diferencia existente, entre el ingreso neto total proveniente de dichas operaciones y el costo computable de los bienes enajenados".

Podría suponerse en un principio que lo sujeto a comparación sería el monto de la indemnización justipreciada, en relación al valor del inmueble en la actualidad; no obstante, serían montos casi equivalentes, puesto que se está comparando en una 
situación actual, solo diferenciándolo en que en la indemnización se agrega la compensación por los daños y perjuicios que se pudiera ocasionar.

En cambio, al compararse la indemnización justipreciada en relación al costo de adquisición (actualizado con índices inflacionarios), se verificará si es que hay una ganancia, la cual, es lo que deberá estar gravado con el Impuesto a la Renta, según la SUNAT, es decir, lo que se gravará será la renta, no la propiedad del bien (patrimonio).

b) Otro argumento, para la SUNAT, que sustenta su gravamen, es en relación al derecho de propiedad, indicando que se admiten límites frente a un derecho fundamental, como lo es el deber de contribuir, reconocido incluso en diversas sentencias del Tribunal Constitucional.

El derecho fundamental de propiedad no es un derecho absoluto, por lo que admite restricciones en atención a su función social, como lo es, el deber de contribuir; el cual, tiene como presupuesto a la capacidad contributiva. Un particular tiene el deber de contribuir al sostenimiento de las cargas públicas, siendo que el Estado no le puede exigir más de lo que él pudiera tributar.

En relación con el caso de la STC No 00319-2013-PA/TC, que trata sobre si debía gravarse o no con el Impuesto a la Renta a la indemnización justipreciada, recibida como consecuencia de la expropiación sufrida por el sujeto pasivo (Sociedad Agrícola San Agustín S.A.) del Fundo San Agustín para la futura ampliación del Aeropuerto Jorge Chávez en Lima; la Administración Tributaria, en sus argumentos como parte demandada, señaló que al momento de verificar si el particular ha contribuido con el pago del impuesto, se determina no en relación al patrimonio; sino, de las posibles rentas o ganancias que haya obtenido en relación con los bienes sujetos a expropiación; en otras palabras, no se grava el patrimonio o propiedad de dichos bienes, sino la posible ganancia generada por el mayor valor recibido por el inmueble respecto a lo que le costó adquirir el mismo.

La SUNAT indica, con especial énfasis para el caso específico de rentas empresariales, que la indemnización justipreciada será un ingreso para las empresas y, solo en la medida que pueda derivar en una ganancia, será gravada la misma con el Impuesto a la Renta. Como indica la SUNAT, esto se dará luego de deducir los costos y gastos respectivos.

c) Asimismo, otro argumento, que la Administración Tributaria indicó, en relación a dicha STC $\mathrm{N}^{\circ}$ 00319-2013-PA/TC, fue que si se llegara a declarar fundada dicha 
Sentencia (como exactamente sucedió), se estaría concediendo un beneficio por vía jurisprudencial lo cual atentaría contra el principio de reserva de ley establecido en el artículo $74^{\circ}$ de la Constitución.

Estos argumentos principales, que establece la Administración Tributaria, consideramos que podrían ser valederos, teniéndose en cuenta que se está tratando de derechos y deberes fundamentales, ya sea el derecho de propiedad y, también, el deber de contribuir, constituyendo una restricción constitucionalmente válida a dicho derecho de propiedad.

Es de precisar, que de los argumentos vertidos por la Administración Tributaria, lo más resaltante sería que no se va a considerar gravada la indemnización justipreciada en su totalidad; sino, la diferencia resultante de comparar dicha indemnización recibida por el Estado, en relación al costo de adquisición del bien, es decir, esa diferencia, sería lo gravado. Considerándose, por tanto, como una ganancia de capital; lo cual, sería un índice de manifestación de riqueza que denotaría capacidad contributiva y, por tanto, que se pueda desplegar el deber de contribuir hacia el particular.

\subsubsection{Argumentos que sustentan su no gravamen con el Impuesto a la Renta}

Los argumentos que sustentan su no gravamen son los principalmente vertidos por el Tribunal Constitucional; asimismo, por los propios particulares (los que actúan en calidad de sujetos pasivos del proceso de expropiación), quienes se verían beneficiados con el no gravamen de la indemnización justipreciada o, mejor dicho, con la diferencia resultante de la comparación de dicha indemnización con el costo de adquisición que tuvo ese bien al momento de adquirirse por el particular, si es que se diese.

En la Sentencia del TC $\mathrm{N}^{\circ}$ 00319-2013-PA/TC, que se mencionó en el subcapítulo anterior, donde la parte demandante era la Sociedad Agrícola San Agustín, lo que solicitaba era precisamente la inaplicación del artículo $5^{\circ}$ del TUO de la LIR, el cual expresa: "Para los efectos de esta ley, se entiende por enajenación la venta, permuta, cesión definitiva, expropiación, aporte a sociedades y, en general, todo acto de disposición por el que se transmita el dominio a título oneroso".

Entre los argumentos más resaltantes, inferidos del Tribunal Constitucional; para sustentar el no gravamen con el Impuesto a la Renta serían:

a) El proceso expropiatorio se caracteriza por ser compulsivo y limitado al pago de una indemnización justa. 
Se critica en ese sentido el artículo $5^{\circ}$ del TUO de la LIR, puesto que se está equiparando en un solo artículo a figuras con características distintas. Un contrato de compraventa, se caracteriza por tener la característica de ser voluntario en su realización, no se obliga a las partes a realizarlo. Lo cual, es diferente a una expropiación, primero, porque no se está en una relación de igualdad de condiciones, ya que es una relación del Estado con el particular (sujeto pasivo) y, donde la voluntariedad se ve mermada para el particular, al coaccionarlo a que transfiera su bien al Estado. La expropiación tiene un carácter forzoso, lo cual no permite la libertad de negociación.

b) Asimismo, el penúltimo párrafo del artículo $3^{\circ}$ del TUO de la LIR trata sobre lo qué se debe entender cuando se grava la renta de las empresas, entendiéndose, como cualquier ganancia o ingreso derivado de operaciones con terceros; en relación a lo cual, el artículo $1^{\circ}$ del RLIR, lo específica, indicando que se entiende por ello "el devenir de la actividad de la empresa en sus relaciones con otros particulares"; siendo que, en la expropiación no se está en una relación así, sino una de las partes es necesariamente el Estado quien no actúa en igualdad de condiciones.

c) Un aspecto resaltante y, que se trató, es la naturaleza del justiprecio. El Tribunal Constitucional recalcó, en sus fundamentos, que dicha naturaleza se encuentra destinada a buscar el equilibrio económico del sujeto pasivo. Asimismo, indicó que el particular se debe encontrar en una situación de equilibrio, es decir, que no sufra pérdida, pero tampoco beneficio alguno.

Tomando una posición contraria a la de la Administración Tributaria, considera que no puede apreciarse como una ganancia de capital; sino, como una reparación de aquello que formaba parte de la propiedad del particular, por ello, no habría renta.

d) El Tribunal Constitucional remarcó, que una transferencia forzosa, como la dada en el proceso de expropiación, no genera señales de capacidad contributiva, pues el monto dinerario recibido solo tiene como destino el equilibrio patrimonial del sujeto pasivo, es decir, que se mantenga indemne el patrimonio del particular. Que pueda terminar en una situación igual a la que tenía antes de la expropiación.

Como se puede apreciar, los argumentos para sustentar su no gravamen con el Impuesto a la Renta, se sintetizan, en que el sujeto pasivo del proceso de expropiación debe ser compensado de tal manera que se mantenga indemne su respectivo patrimonio. Es decir, no debe encontrarse en una situación de afectación, con la disminución de su patrimonio 
producto de la expropiación; sino, que debe haber un justo equilibrio, que no se le perjudique, ni beneficie.

Por tanto, al mantenerse en una posición de no gravarse la indemnización justipreciada con el Impuesto a la Renta, se está tomando un enfoque de no considerarlo como ganancia de capital, es decir, en esta postura o posición, el sujeto pasivo no se beneficia, ni perjudica; sino, que se está en una situación de equilibrio, donde lo importante es mantener indemne el patrimonio del sujeto pasivo.

Se puede apreciar de los fundamentos de la Administración Tributaria, con especial referencia en los vertidos en la STC $\mathrm{N}^{\circ}$ 00319-2013-PA/TC, que se centraliza el concepto de enajenación, regulado en el artículo $5^{\circ}$ del TUO de la LIR. Al revisar sus argumentos, podríamos cuestionarnos si la Administración Tributaria tomó, o no, en cuenta, el ámbito de aplicación de dicho artículo; sobre todo, en el aspecto material o sustantivo, para poder determinar qué es lo que estaría gravado con el Impuesto a la Renta.

\subsection{Posiciones doctrinarias en relación a la afectación de la indemnización} justipreciada con el impuesto a la renta

\subsubsection{Posición del Tribunal Constitucional}

El Tribunal Constitucional, en relación al procedimiento de expropiación, ha tomado una posición de respeto a los derechos fundamentales, tomando en cuenta a su vez los requisitos necesarios para que se lleve a cabo una adecuada expropiación regulados, en el momento que se dictó la STC Nº 00319-2013-PA/TC, en la Ley Nº 27117 (1999); actualmente, en el D.L. N 1192 (2015).

En la STC N05312-2009-PA/TC, por ejemplo, en el fundamento jurídico $\mathrm{N}^{\circ} 8$, se indica de manera expresa, que el derecho de propiedad no puede ser limitado de manera arbitraria; sino, solo por causas reales y apremiantes como la seguridad nacional o necesidad pública declarada por ley expresa del Congreso en favor del Estado, y previo pago en efectivo de la indemnización justipreciada que incluya compensación por el eventual perjuicio; ello, a raíz, de un proceso de expropiación dado entre el Estado y el propietario de una planta pesquera (Pesquera San Martín de Porres), siendo dicho inmueble materia de expropiación; no obstante, el sujeto pasivo no había recibido 
la respectiva indemnización justipreciada. (STC $\mathrm{N}^{\circ}$ 05312-2009-PA/TC, f.j. $\mathrm{N}^{\circ} 8$, 2009).

Asimismo, en la STC $\mathrm{N}^{\circ}$ 05614-2007-PA/TC, en el fundamento jurídico $\mathrm{N}^{\circ} 12$, se trató sobre un aspecto que no ha sido tan discutido en el Tribunal, el cual es, "la expropiación de hecho". En este aspecto, el Tribunal ha sido muy enfático sosteniendo que este tipo de expropiaciones son inconstitucionales, puesto que no tienen una base en los derechos fundamentales que son el pilar en un Estado Democrático de Derecho. El Tribunal en dicho considerando expresó:

Así pues, las entidades de la Administración Pública tienen el deber constitucional de respetar el derecho de propiedad.

Por consiguiente, cuando requieran bienes inmuebles deben obrar con sujeción al principio de legalidad y al derecho al debido proceso, es decir, para que el derecho de propiedad pueda ser adquirido válidamente mediante el acto de expropiación, se requiere que exista una ley del Congreso de la República que exprese alguno de los motivos contemplados en la Constitución para que proceda la expropiación. Por ello, los actos de expropiación de hecho resultan inconstitucionales. (STC Nº 05614-2007PA/TC, f.j. $\mathrm{N}^{\circ} 12,2009$ ).

Asimismo, el Tribunal ha tomado en cuenta la importancia del previo pago del justiprecio o indemnización justipreciada indicándose, por ejemplo, en la STC $\mathrm{N}^{\circ}$ 00864-2009-PA/TC, en el fundamento jurídico $\mathrm{N}^{\circ} 33$ :

El último acto administrativo que correspondía se incumplió. No existió la emisión de la resolución de expropiación, hecho que acarrea una clara vulneración al derecho a la propiedad constitucionalmente reconocida, y que si bien es un derecho con límites, dentro de los cuales se encuentra la expropiación, esta solo puede ser considerada como razonable, mientras se realice dentro de los parámetros normativos existentes, los cuales no han sido respetados por el órgano administrativo, en cuanto a la finalización del acto administrativo que consistía en el pago del justiprecio. (STC N 00864-2009-PA/TC, en el f.j. $\left.N^{\circ} 33\right)$.

En las Sentencias anteriores, se ha reseñado la importancia que da el Tribunal en el cumplimiento de los requisitos formales, para que se dé un adecuado proceso de expropiación; en la STC N 00319-2013-PA/TC también se trata este aspecto.

Esta Sentencia se derivó de un Recurso de Agravio Constitucional interpuesto por la Sociedad Agrícola San Agustín S.A. Lo que se solicitaba era la inaplicación, para el caso concreto, del artículo $5^{\circ}$ del T.U.O. de la LIR, por una supuesta amenaza de 
vulneración al derecho de propiedad de dicha parte demandante, respecto a la indemnización justipreciada recibida por parte del Estado. Es decir, si debía gravarse o no con el Impuesto a la Renta a la indemnización justipreciada, recibida como consecuencia de la expropiación sufrida por el sujeto pasivo (Sociedad Agrícola San Agustín S.A.) del Fundo San Agustín para la futura ampliación del Aeropuerto Jorge Chávez en Lima.

La Sentencia trató aspectos como el mantenimiento del justo equilibrio en el patrimonio del sujeto pasivo de la expropiación; asimismo, de la coacción que se da en esta figura de la expropiación, en relación con otras figuras como la compraventa, por ejemplo.

El Tribunal resalta en sus fundamentos jurídicos (específicamente en el Fundamento Jurídico $\mathrm{N}^{\circ}$ 30) que lo estipulado en el artículo $5^{\circ}$ de la LIR "no se identifica como un hecho imponible del impuesto a la renta, pues la naturaleza del pago de la indemnización justipreciada se encuentra destinada a buscar el equilibrio económico del sujeto pasivo de la expropiación, mas no la generación de renta”.

Se indica que en el proceso de expropiación se priva de una etapa de negociación, que permita al Estado y al particular obtener un beneficio económico, puesto que el uso de esta potestad se limita al desarrollo de obras en beneficio del interés general (razones debidamente especificadas y motivadas) y no a una generación de ingresos.

El principal argumento que indica el Tribunal, que es sostenido a lo largo de la Sentencia, es que el pago que se realiza producto de la expropiación, solo busca el equilibrio económico del sujeto pasivo por la pérdida que sufre del bien.

Consideramos que el Tribunal debió ahondar más, pronunciándose en aspectos como el ámbito de aplicación del Impuesto a la Renta, puesto que, precisamente, se estaba cuestionando la inaplicación del artículo $5^{\circ}$ de la LIR; asimismo, su vinculación con lo qué se entiende por renta gravada de las empresas, especificando, si cuando el Estado le expropia un bien a una empresa podría considerarse, el pago del justiprecio que el Estado le da al particular, una renta gravada; teniéndose en cuenta, que no hay una igualdad de condiciones, puesto que las partes eran el Estado frente a una empresa (Sociedad Agrícola San Agustín S.A.). 


\subsubsection{Posición de la Administración Tributaria}

La Administración Tributaria, sobre el tema de la expropiación, ha emitido diversos Informes.

El más antiguo, relativamente, es el Informe $\mathrm{N}^{\circ}$ 314-2005-SUNAT/2B0000, el cual trata acerca de un proceso de expropiación, cuando el sujeto pasivo es una persona natural, lo cual ocurrió en el año 1998. Es de precisar, que la Administración Tributaria, en ese entonces, no alude al término de "ganancia de capital", puesto que como afirma Villanueva (2007), es recién en el año 2004, cuando se la incluye como renta gravable con carácter general para efectos del Impuesto a la Renta. (p. 350).

El Informe $\mathrm{N}^{\circ}$ 142-2010-SUNAT/2B0000 indicó que "la totalidad de los ingresos provenientes de la indemnización justipreciada y de las prestaciones indemnizatorias adicionales en caso de expropiaciones para obras de infraestructura de servicios públicos deberá sujetarse al tratamiento de las ganancias de capital derivadas de una enajenación" (p. 5).

Es decir, como sostiene la Administración Tributaria, los importes que provengan de la transferencia por expropiación de un bien, que constituya un activo no destinado a la comercialización en el ámbito de un giro de negocio o de empresa, deberá recibir el tratamiento de ganancia de capital, sustentado en base a la teoría del flujo de riqueza.

En igual sentido, el Informe $\mathrm{N}^{\circ}$ 91-2014-SUNAT/5D0000, sustentado en el Informe anterior, también refiere que:

La totalidad de los ingresos provenientes del precio a pagarse por todo concepto para la adquisición de inmuebles como consecuencia de su expropiación por trato directo, a que se refieren las Leyes $\mathrm{N}^{\circ} 27628$ [denominada Ley que facilita la ejecución de obras públicas viales, (2002)] y la $\mathrm{N}^{\circ} 30025$ (2013), se encuentran gravadas con dicho impuesto, debiendo sujetarse al tratamiento de las ganancias de capital, derivadas de una enajenación. (p. 3)

Recientemente, se ha emitido el Informe $N^{\circ}$ 0149-2015-SUNAT/5D0000, el cual trata el tema de la expropiación, pero ahora tomando en cuenta su nueva regulación, es decir, basado en el D.L. $\mathrm{N}^{\circ} 1192$ (2015). Este Informe, que ya lo comentamos en el subcapítulo anterior, también tuvo otra consulta, la cual era sobre la determinación del Impuesto a la Renta. 
Se debe resaltar, que en los anteriores Informes de la Administración Tributados relacionados a este tema de la expropiación, se ha llegado a la conclusión de considerar gravada la indemnización justipreciada bajo el tratamiento de ganancias de capital, con lo cual, lo que estaría afecto con el Impuesto sería la posible renta generada a raíz de dicha indemnización, en la medida que el monto recibido sea mayor al costo de adquisición del bien (actualizado en base a las normas de ajuste por inflación con incidencia tributaria); es decir, es esa plusvalía o incremento lo que se encontrará afecto con el Impuesto, pero no la indemnización justipreciada como tal.

Lo que se puede decir frente a estos Informes es que, al igual que la Sentencia del Tribunal Constitucional, no se trató un tema esencial en torno al Impuesto a la Renta, como es el ámbito de aplicación de dicho Impuesto, en una situación como la dada en la expropiación.

Si bien en los Informes se concluyó, que los bienes sujetos a expropiación sí estarían gravados con el Impuesto a la Renta, sujetándose al tratamiento de las ganancias de capital, lo cual creemos podría ser correcto; no se indicó, por qué la transferencia de un bien, entre un Estado y un particular, tendría que estar gravada o no con dicho Impuesto, solo se remitió la Administración Tributaria, a decir, que al ser un ingreso, que proviene de la enajenación de un bien no destinado a la comercialización en el ámbito de su giro de negocio o empresa, sería sujeto al tratamiento de las ganancias de capital; sin especificarse, sobre el ámbito de aplicación, tanto objetivo como subjetivo, es decir, en el caso que se está tratando en este trabajo, sobre una expropiación de bien inmueble que se caracteriza por no haber una igualdad de condiciones entre las partes.

\subsubsection{Posición del Congreso de la República}

El Congreso de la República, mediante distintos Proyectos de Ley, ha expresado sus diversos puntos de vista, los cuales los ha dado a conocer. En las respectivas Exposiciones de Motivos de dichos Proyectos, ha tomado en cuenta las diversas posiciones, como el de la Administración Tributaria, indicándose respecto a ésta:

El tema es relevante toda vez que cuando se expropia, para la SUNAT y la ley es aplicable el Impuesto a la Renta a la expropiación. No hay una precisión clara sobre el pago del Impuesto a la Renta, que si bien, con la sentencia del Tribunal Constitucional 
se inaplica el artículo $5^{\circ}$ del T.U.O. del TUO de la Ley del Impuesto a la Renta, tampoco es la solución general. (Proyecto de Ley Nº 03026/2013-CR)

Asimismo, en relación a la actualmente derogada Ley $N^{\circ} 30025$ (2013), la cual reconocía de manera expresa una indemnización justipreciada, sostiene:

Con la vigencia de la Ley $\mathrm{N}^{\circ} 30025$, se reconoce una indemnización justipreciada, conforme lo establece el artículo 5.1, literal b y en la Tercera Disposición Modificatoria. Esta disposición tampoco precisa que el justiprecio por expropiación está inafecta al impuesto a la renta, por lo que es necesario proponer que cuando se trate de una indemnización por expropiación está inafecta por el impuesto a la renta. (Proyecto de Ley $\mathrm{N}^{\circ}$ 03026/2013-CR)

Dicho Proyecto de Ley N ${ }^{\circ}$ 03026/2013-CR señala, en su Exposición de Motivos, otros argumentos, como el que si existiera contradicción entre lo expresado en el artículo $5^{\circ}$ del TUO de la LIR y, lo señalado, en la Tercera Disposición Final de la Ley General de Expropiaciones (Ley $\mathrm{N}^{\circ}$ 27117, actualmente derogada), se podría aplicar el principio de que la ley especial prima sobre la general.

Otro argumento que se indicó sobre esta norma actualmente derogada, es en relación a la dicha Tercera Disposición Final de la Ley № 27117 (1999), la cual señalaba: "Las enajenaciones por causa de expropiación quedan expresamente excluidas del ámbito de aplicación de todos los tributos que graven transferencias”. No obstante, frente a lo afirmado por esta Disposición, se podría refutar ello, haciendo una interpretación literal de la misma, puesto que, como señala la Exposición de Motivos, la frase "tributos que graven transferencias", podría descartar al Impuesto a la Renta, ya que éste no grava transferencias, sino la renta obtenida.

Por estos argumentos, en los cuales no se tiene claro si es que hay o no una afectación al Impuesto a la Renta cuando se da el pago de una indemnización justipreciada, es que dicho Proyecto, tenía como objetivo, que se precise de manera directa en la Ley $\mathrm{N}^{\circ} 27117$ (1999), que el valor del justiprecio no está afecto al Impuesto a la Renta.

Posteriormente, se dio el Proyecto de Ley $\mathrm{N}^{\circ}$ 03352/2013-CR, presentado el 04 de abril de 2014, el cual tenía el propósito de modificar el artículo $15^{\circ}$ de la Ley $\mathrm{N}^{\circ}$ 27117 (1999).

Este Proyecto iba en el mismo sentido que el anterior, puesto que se quería especificar, de manera expresa, con la incorporación de un numeral en dicho artículo, 
que el pago de la indemnización justipreciada por expropiación, esta inafecta del Impuesto a la Renta.

Los argumentos vertidos en la Exposición de Motivos de este Proyecto siguen la misma posición que dio el Tribunal Constitucional en la STC $\mathrm{N}^{\circ}$ 00319-2013-PA/TC. Se indicó, que el objetivo no era que se configure un beneficio económico; sino, lo que se quería es que el particular mantenga la situación económica que tenía antes de la expropiación, por lo que, al encontrarse en una situación de equilibrio, no se generaría capacidad contributiva, con lo cual no sería de aplicación el deber de contribuir por parte del sujeto pasivo (el particular).

El 12 de junio se presentó el Proyecto de Ley $N^{\circ}$ 03602/2013-CR que tenía como propósito el que se dé una "Ley de Inafectación del Impuesto a la Renta a la Indemnización Justipreciada pagada por el Estado en las Expropiaciones". En ese sentido, lo que se quería era que no sea de aplicación general el artículo $5^{\circ}$ del TUO de la LIR, y no solo basándose en la STC N 00319-2013-PA/TC, que al ser un Proceso de Amparo, era de aplicación para el caso concreto de dicha Sentencia.

\subsubsection{Posición de diversos Juristas}

La posición de diversos juristas es, en su mayoría, parecida a la que tuvo el Tribunal Constitucional en la STC N 00319-2013-PA/TC.

Juristas como Domingo García Belaúnde, Fernando de Trazegnies o Humberto Medrano, entre otros; son de la posición que la afectación con el Impuesto a la Renta, a la indemnización justipreciada, vulnera el derecho fundamental a la propiedad.

De Trazegnies (2012), sostuvo que cuando al particular se le expropia nadie le "propone" una compra; sino, que simplemente se establece una indemnización y se le paga. Es de resaltar, que dicho jurista expresa este parecer, no considerando el costo de adquisición que desembolsó el particular; sino, solo supone que al momento de pagarse el justiprecio lo que habría sería una transferencia forzosa de la propiedad de un bien, por una suma de dinero que se considera equivalente al valor de dicha propiedad expropiada. No obstante, antes de esto último, creemos que es necesario analizar el ámbito de aplicación en el que se desarrolla la relación que se da entre el Estado y el particular. 
Argumentos, como que el particular tiene que encontrarse en una situación de indemnidad, es decir, sin carga alguna; así como, el respeto a los derechos fundamentales, son expresados por García Belaunde (2013), quien indica que la expropiación "es un daño que el Estado infringe a los particulares en uno de sus derechos fundamentales" (derechos de propiedad); con lo cual, habría una transgresión manifiesta.

Medrano (2013) es de la posición que en la expropiación, el titular del bien inmueble no lo está transfiriendo de manera voluntaria; sino, que se encuentra constreñido a transferirlo. A su vez, propuso que lo más sencillo sería indicar de manera directa en el TUO de la LIR que quien es el sujeto pasivo en un proceso de expropiación no incurre en enajenación, con lo cual, lo recibido por parte del Estado no sería gravable. Otra medida, que indicó en su comentario, sería el hacer un gross up [cursivas añadidas], es decir, que si se tuviera como indemnización justipreciada un determinado monto, se considere éste más el $28 \%$ de dicho monto, siendo que al aplicarse el impuesto a la Renta (en el caso el sujeto pasivo sea una empresa), no vería rebajado dicho monto, puesto que se ha añadido el equivalente al impuesto que tendría que tributar (actualmente con una tasa del $28 \%$ ).

\subsubsection{Nuestra Posición}

La posición que hemos tomado y, que se ha ido apreciando en los acápites anteriores, es el de analizar el proceso de expropiación vinculándolo con el ámbito de aplicación del Impuesto a la Renta, es decir, verificar si hay o no renta gravada al realizarse dicho proceso.

Consideramos que la indemnización justipreciada que se pague al particular, producto de la expropiación, debe ser analizada tomando en cuenta las distintas normas que la regulan; haciendo una diferencia entre si el sujeto pasivo del impuesto es una persona natural o persona jurídica, es decir, si el contribuyente es perceptor o no de renta empresarial.

Es relevante especificar, que si el sujeto pasivo en un proceso de expropiación fuera una persona natural, consideramos, que podría encontrarse la indemnización justipreciada que le diera el Estado al particular, afectada con el Impuesto a la Renta, bajo el tratamiento de ganancia de capital. 
No obstante, es de precisar, que se debe considerar la excepción señalada en el último párrafo del artículo $2^{\circ}$ del TUO de la LIR, el cual precisa, que si el bien inmueble es ocupado como casa habitación del enajenante (es decir, del sujeto pasivo) no será considerado como ganancia de capital. Asimismo, lo señalado en la $35^{\mathrm{a}}$ Disposición Transitoria y Final del TUO de la LIR, especificado, por el numeral 1, de la $1^{a}$ Disposición Transitoria del Decreto Supremo N ${ }^{\circ}$ 86-2004-EF en el cual se indica que "no estará gravada con el Impuesto, la enajenación de inmuebles cuya adquisición se haya realizado con anterioridad al 1 de enero de 2004, a título oneroso o gratuito, mediante documento de fecha cierta".

En cuanto a las personas jurídicas, aquí el tratamiento podría ser distinto, si bien el artículo $5^{\circ}$ del TUO de la LIR define el concepto de enajenación, sosteniendo que la expropiación es un supuesto de aquella, podría considerarse con dicha regulación como una ganancia de capital expresa. No obstante, en el mismo Capítulo I (Ámbito de Aplicación) del TUO de la LIR, también se encuentra el penúltimo párrafo del artículo $3^{\circ}$, el cual indica que "constituye renta gravada de las empresas, cualquier ganancia o ingreso derivado de operaciones con terceros"; este concepto es muy importante, puesto que el mismo TUO de la LIR precisa que las ganancias que se derivan de esas operaciones estarán afectas con el Impuesto a la Renta.

Reforzando esta posición, el artículo 1, inciso g) del RLIR especifica que dicha ganancia o ingreso derivado de operaciones con terceros "se refiere a la obtenida en el devenir de la actividad de la empresa en sus relaciones con otros particulares, en las que los intervinientes participan en igualdad de condiciones y consienten el nacimiento de las obligaciones".

Entonces, frente a esta regulación del TUO de la LIR, como del RLIR, se podría inferir que la indemnización justipreciada en el proceso de expropiación o, mejor dicho, la diferencia resultante de comparar dicha indemnización con el respectivo costo de adquisición del bien no estaría gravada para el caso de rentas empresariales.

Siguiendo esta posición, consideramos que en el caso de que el sujeto pasivo sea una empresa, se podría sustentar que no habría gravamen con el Impuesto a la Renta a dicha indemnización justipreciada que reciba, puesto que, en la expropiación, los intervinientes no se encuentran en una igualdad de condiciones, ya que es el Estado con su poder de Ius Imperirum, quien coacciona al particular para que transfiera su propio 
bien inmueble. Es decir, hay una situación de superioridad con respecto al particular, donde no se presenta como estamos sosteniendo una igualdad de condiciones.

La igualdad de condiciones es un punto central en nuestro análisis, puesto que podría afirmarse, que al no haber una relación entre particulares, no se podría considerar el ingreso derivado de dicha expropiación como "un ingreso derivado de operaciones con terceros" y, por tanto, podría inferirse que no se constituiría en una renta gravada de las empresas.

Creemos que el Tribunal Constitucional en la STC N 00319-2013-PA/TC debió determinar el ámbito de aplicación del Impuesto a la Renta, específicamente, el aspecto material del Impuesto, si se está tratando o no de una renta, para luego determinar si ésta resultaba gravada o no, tanto para el caso de rentas empresariales como no empresariales; aunque con mayor razón para las rentas empresariales, puesto que podría no encontrarse gravado con dicho Impuesto por este concepto de ingreso derivado de operaciones con terceros [cursivas añadidas].

En ese sentido, para realizar lo señalado en el párrafo anterior, el Tribunal Constitucional tendría que haber analizado la relación que se da entre el Estado y el particular en el proceso de expropiación y, vincularlo, con el penúltimo párrafo del artículo $3^{\circ}$ del TUO de la LIR, para el caso de rentas empresariales, es decir, darle un significado a este concepto de "ingreso derivado de operaciones con terceros".

Considero que el Tribunal Constitucional debió tratar este aspecto señalado en el párrafo anterior, en vez de sustentar con otros argumentos, que no estaban tan vinculados con el ámbito de aplicación del Impuesto a la Renta.

Creemos, por tanto, que frente a la problemática de si estaría o no gravado con el Impuesto a la Renta, el pago que el Estado le hace al particular, para el caso de que el particular sea una empresa, podría suponerse que no se encuentre afecto al Impuesto a la Renta si tomamos el concepto de "ingreso derivado de operaciones con terceros".

\subsection{Conclusiones parciales}

- La expropiación, constituye un límite al derecho de propiedad, el cual está reconocido de manera constitucional y legal en el Perú.

- Para que se lleve a cabo un adecuado proceso de expropiación, se deben cumplir ciertos requisitos, como el que solo puede darse por causas excepcionales como 
la seguridad nacional o necesidad pública, que sea autorizada por ley expresa del Congreso; así como, el que se haga el pago previo de la indemnización justipreciada antes de la transferencia forzosa del bien del particular, siendo el único beneficiario el Estado con su realización.

- La indemnización justipreciada que el Estado le da al particular, se encuentra regulado en el artículo $13^{\circ}$ del D.L. $\mathrm{N}^{\circ} 1192$ (2015), la cual comprende el valor comercial del inmueble debidamente actualizado y, la compensación que se debe abonar en caso de acreditarse de manera fehaciente daños y perjuicios para el sujeto pasivo.

- Se tiene un consenso en base a la regulación peruana, los Informes de la Sunat; así como, de la opinión de diversos juristas, que la indemnización que se otorgue por daños emergentes no está gravada tanto para perceptores, como no perceptores de rentas de tercera categoría.

- Uno de los argumentos más relevantes para considerarse gravada la indemnización justipreciada con el Impuesto a la Renta se encuentra, en que lo que se grava es la ganancia de capital y no, la indemnización justipreciada como tal, lo cual es índice de capacidad contributiva, que se sustenta en el segundo párrafo del artículo $20^{\circ}$ del TUO de la LIR.

- Entre los argumentos, para considerarse no gravada la indemnización justipreciada con el Impuesto a la Renta, se encuentran los vertidos por el Tribunal Constitucional (a raíz de su Sentencia emitida, la $N^{\circ}$ 00319-2013$\mathrm{PA} / \mathrm{TC}$ ), donde el Colegiado sostiene que lo qué se busca con dicho pago es solo el equilibrio económico del sujeto pasivo, a raíz de la pérdida de su bien.

- El penúltimo párrafo del artículo $3^{\circ}$ del TUO de la LIR y, el inciso g) del artículo $1^{\circ}$ del RLIR tendrían relevancia para no considerar gravada la indemnización justipreciada, teniéndose en cuenta, que la expropiación es una relación entre el Estado y el particular en la que no hay igualdad de condiciones.

- Existen diversas opiniones en torno a la problemática de si la indemnización justipreciada resultaría gravada o no con el Impuesto a la Renta, tanto del Tribunal Constitucional, como de la Administración Tributaria, del Congreso de la República, entre otros. 
- La Administración Tributaria encuadra a dicha indemnización justipreciada al tratamiento de las ganancias de capital.

- Al cerciorarse si está gravada o no la indemnización justipreciada, debemos analizar primero qué es lo que sería renta, analizar el aspecto material del impuesto, enfocándonos en el ámbito de aplicación del mismo.

- En el caso de rentas empresariales, un concepto que hay que tener en cuenta es "el ingreso derivado de operaciones con terceros", expresado en el mencionado penúltimo párrafo del artículo $3^{\circ}$ del TUO de la LIR.

- Para el caso de rentas no empresariales, podría darse el tratamiento de ganancia de capital, siempre analizando el caso concreto en relación con las teorías de renta; $y$, tomándose en cuenta, las excepciones al tratamiento de las ganancias de capital en personas naturales, sucesiones indivisas o sociedades conyugales que optaron por tributar como tales (que el inmueble constituya casa habitación del sujeto particular y que sean inmuebles adquiridos antes del 1 de enero de 2004). 


\section{CONCLUSIONES}

De todo lo dicho en el presente trabajo de investigación, se pueden extraer las siguientes conclusiones:

- Dentro de las tres teorías de renta ampliamente difundidas en el Perú, la que más se involucra en el análisis del proceso de expropiación es la teoría del flujo de riqueza, puesto que incluye la totalidad de los ingresos provenientes de terceros.

- Al realizar el análisis que se plantea en este trabajo, acerca de si la indemnización justipreciada estaría o no gravada con el Impuesto a la Renta, se debe partir por cerciorarse de si el presupuesto de hecho se ajusta a la hipótesis de incidencia. Es decir, analizar si el concepto de indemnización justipreciada se ajusta al aspecto material del Impuesto a la Renta.

- Luego de enfocarnos en el ámbito de aplicación, se tiene que hacer un análisis más específico, agrupando en rentas empresariales y no empresariales, puesto que cada uno tiene consideraciones distintas, en relación al tratamiento del proceso de expropiación.

- Analizar el ámbito de aplicación implica, si dicha indemnización justipreciada o justiprecio puede ser sujeta a gravamen, se analizará qué parte es la que se grava con el impuesto, teniéndose en cuenta que la ganancia resultaría de la diferencia entre el pago recibido por el Estado al particular (justiprecio) y el costo de adquisición (debidamente actualizado).

- Cuando se trata de rentas empresariales, el TUO de la LIR indica que será renta gravada, "cualquier ganancia o ingreso derivado de operaciones con terceros". El RLIR, en el artículo $1^{\circ}$, inciso g), específica este último concepto, refiriéndose a lo “obtenido en el devenir de la actividad de la empresa en sus relaciones con otros particulares, en la que los intervinientes participan en igualdad de condiciones y consienten el nacimiento de obligaciones".

- Esta expresión de "ingreso derivado de operaciones con terceros", la cual es desarrollada por el RLIR, se entiende que se aplica a situaciones en donde existe consentimiento en el nacimiento de las obligaciones entre particulares. Se ha dado 
la voluntariedad en las partes para llevarlas a cabo. No obstante, dicha norma en el RLIR, ha recibido cuestionamientos, como el que podría estarse transgrediendo el principio de legalidad; por otro lado, se ha argumentado que lo sostenido en el RLIR no tiene carácter restrictivo.

- Es muy importante delimitar la expresión "ingreso derivado de operaciones con terceros", analizando el caso en concreto, cuál es la operación en específico que realizan las partes (puesto que podrían presentarse situaciones donde el Estado podría actuar en igualdad de condiciones frente al particular); enfatizando, el aspecto personal o subjetivo, siendo que, en el caso de la expropiación se da una relación entre el Estado y el particular, éste último en calidad de sujeto pasivo.

- En la relación entre el Estado y el particular, es frecuente que los beneficios nazcan por un mandato legal (por ejemplo, el régimen aduanero del Drawback, las condonaciones que hace el Estado de tributos, como la dada en la RTF $\mathrm{N}^{\circ}$ 616-41999 la cual es Jurisprudencia de Observancia Obligatoria, etc.), en el sentido, de que no hay un acuerdo consentido de las partes para la obtención de dichos beneficios.

- Precisamente, una relación en la que no hay "igualdad de condiciones", es en la expropiación, donde se da una relación entre el Estado y el particular. Para llevarla a cabo, se deben cumplir ciertos requisitos, siendo uno de los más resaltantes el que solo se lleve a cabo por razones como la seguridad nacional o necesidad pública.

- Un argumento resaltante para no considerar gravada la ganancia de capital resultante (en cuanto a rentas empresariales), con el Impuesto a la Renta; es indicar, que la expropiación no se trata de una operación entre particulares, puesto que no hay una igualdad de condiciones. Las resoluciones del Tribunal Fiscal han recalcado esta situación, por ejemplo en lo referente al régimen aduanero del Drawback, donde dicho Tribunal resalta que dicho beneficio nace por imperio de la Ley (en virtud del Ius Imperium del Estado), es decir, por un mandato legal, concluyéndose que habría afectación con el Impuesto a la Renta por tratarse de un subsidio otorgado por el Estado y no dado por un consentimiento de ambas partes.

- Es importante recalcar, que la figura de la expropiación, para que se lleve a cabo de manera adecuada, debe cumplir una serie de requisitos actualmente vigentes en el Decreto Legislativo $\mathrm{N}^{\circ} 1192$ (2015), siendo entre éstos requisitos el que solo sea 
autorizada por ley expresa del Congreso de la República, que solo se dé por causas excepcionales como la seguridad nacional o necesidad pública; asimismo, que se cumpla con el pago previo de la indemnización justipreciada (el cual comprende el valor comercial del inmueble actualizado y, el valor del perjuicio económico) al sujeto pasivo de la expropiación; es decir, que reciba dicho valor de la Tasación antes de que se le expropie el bien inmueble al particular.

- En relación a las distintas opiniones vertidas sobre esta problemática, de si la indemnización justipreciada se encontraría afecta al Impuesto a la Renta; la postura que toma la Administración Tributaria, creemos, es la que más se aproxima a lo que nosotros sostenemos; es decir, que no se grave con el Impuesto a la Renta la indemnización justipreciada como tal; sino, la diferencia resultante del mayor valor recibido por el inmueble, respecto a lo que le costó adquirir el mismo, lo que se conoce como ganancia de capital.

- No obstante, si bien sostenemos de que se debe gravar con el Impuesto a la Renta dicha diferencia indicada en el párrafo anterior de estas conclusiones finales, creemos, que la Administración Tributaria no se ha pronunciado sobre aspectos que son fundamentales como el ámbito de aplicación del impuesto, puesto que, por lo general, solo se enfoca en el concepto de enajenación regulado en el artículo $5^{\circ}$ del TUO de la LIR.

- Consideramos que la Administración Tributaria, si bien llegó a una posición que compartimos, sobre qué gravarse con el Impuesto a la Renta, no analizó otros aspectos importantes como el ámbito de aplicación de dicho impuesto, con especial énfasis en el aspecto material, para determinar precisamente qué es lo que se está gravando, si realmente existe renta o no cuando se da un proceso de expropiación.

- Dentro de este ámbito de aplicación, consideramos que el Tribunal Constitucional, como la Administración Tributaria, debieron tomar más énfasis en el análisis del ámbito de aplicación del Impuesto a la Renta. Es decir, que en el proceso de expropiación, específicamente, cuando el Estado le da el pago previo al particular o sujeto pasivo, lo cual será visto como un posible hecho imponible, debe verificarse, si este hecho encuadra o no en la hipótesis de incidencia, lo cual determinará si existe o no un hecho gravado. 
- Tanto la Administración Tributaria, como el Tribunal Constitucional (especialmente, a raíz de su STC $\mathrm{N}^{\circ}$ 00319-2013-PA/TC), sobre si la indemnización justipreciada estaría gravada, tienen opiniones diferentes. La Administración Tributaria o Sunat indica que lo que se grava es la ganancia de capital y no la indemnización como tal; por otro lado, el Tribunal Constitucional, sostiene que con dicho pago al sujeto pasivo, lo que se busca es el justo equilibrio por la pérdida forzosa de su bien.

- Al analizar esta problemática, es importante tomar en cuenta si en la expropiación el sujeto pasivo es un sujeto perceptor o no de rentas de tercera categoría. Puesto que los tratamientos pueden diferir, ejemplo de ello, es lo señalado en el último Informe de la Administración Tributaria sobre el tema de la expropiación (Informe $\mathrm{N}^{\circ}$ 0149-2015-SUNAT/5D0000); asimismo, nuestra posición, también se inclina por este distingo, para de ahí vincular el concepto de ingreso derivado de operaciones con terceros [cursivas añadidas] con los perceptores de renta empresarial.

- En el caso que fuera una persona natural o, mejor dicho, que sea perceptora de rentas no empresariales, consideramos que la indemnización justipreciada se encontraría gravada con el Impuesto a la Renta bajo el tratamiento de las ganancias de capital. No obstante, se deben tomar en cuenta las excepciones en las que no se constituye ganancia de capital, reguladas para el caso de personas naturales, sucesiones indivisas o sociedades conyugales que optaron por tributar como tales, es decir, que sean inmuebles ocupados como casa habitación del sujeto particular (último párrafo del artículo $2^{\circ}$ del TUO de la LIR) o, que hayan sido adquiridos antes del 01 de enero de 2004 (35 DTF del TUO de la LIR).

- Con relación a los perceptores de renta empresarial, generalmente las personas jurídicas, aquí sí podría considerarse no gravada la indemnización justipreciada con el Impuesto a la Renta, si es que nos basamos en el concepto de ingreso derivado de operaciones con terceros [cursivas añadidas]. Si bien, el artículo $5^{\circ}$ del TUO de la LIR indica que la expropiación es un supuesto de enajenación, con lo cual se podría considerar, con dicha regulación, como una ganancia de capital expresa; dicho artículo, debemos interpretarlo o vincularlo con el penúltimo párrafo del 
artículo $3^{\circ}$ el cual se encuentra en el mismo Capítulo I (vinculado al Ámbito de aplicación).

- El penúltimo párrafo del artículo $3^{\circ}$ indica que "constituye renta gravada de las empresas, cualquier ganancia o ingreso derivado de operaciones con terceros"; este concepto es muy importante, puesto que el mismo TUO de la LIR precisa que las ganancias que se derivan de esas operaciones estarán afectas con el Impuesto a la Renta, lo cual es especificado por el artículo 1, inciso g) del RLIR.

- Si tomamos en cuenta estas normas y, realizamos una interpretación sistemática, podría suponerse que para el caso de rentas empresariales, la indemnización justipreciada no estaría afecta al Impuesto a la Renta, es decir, dicha ganancia resultante de comparar el valor de la tasación, en relación con el costo de adquisición del bien no estaría gravado, claro está, si lo vinculamos con lo dispuesto en el penúltimo párrafo del artículo $3^{\circ}$ del TUO de la LIR y el artículo $1^{\circ}$, inciso g) del RLIR.

- Lo expresado en el RLIR, acerca de que "la ganancia o ingreso derivado de operaciones con terceros, se refiere a la obtenida en el devenir de la actividad de la empresa en sus relaciones con otros particulares" es importante en el análisis, puesto que, precisamente como recalcamos, en la expropiación se da una relación en la que el Estado no se encuentra en igualdad de condiciones con el particular.

- El Tribunal Constitucional si bien trató sobre el proceso de expropiación en diversas Sentencias, es especialmente en la STC $\mathrm{N}^{\circ} \circ$ 00319-2013-PA/TC donde utilizó argumentos que no se inclinaban a determinar el ámbito de aplicación del Impuesto a la Renta, es decir, solo se concentró, al igual que la Administración Tributaria o SUNAT, en el concepto de enajenación, pero no se pronuncian acerca de dicho ámbito del Impuesto.

- El principal argumento, del Tribunal Constitucional, es sostener que la indemnización justipreciada busca el equilibrio económico del sujeto pasivo, pero no la generación de renta, por lo que no habría afectación con el Impuesto a la Renta. Frente a lo cual, la Administración Tributaria mantiene una posición de que sí habría afectación, posición que mantiene aun después de la Sentencia emitida por el TC en el año 2013. No obstante, es de precisar, que en ambas posiciones no se 
analiza lo qué significa el concepto de ingreso derivado de operaciones con terceros, especialmente con relación al proceso de expropiación.

- A raíz de todo lo discutido, surgen propuestas de solución, algunas muy directas como, por ejemplo, la indicada por Medrano (2013), en el sentido de que se expida una norma indicando que quien sufre de la expropiación de un(os) inmueble(s), es decir, el sujeto pasivo, no incurra en enajenación, lo que también, fue materia del Proyecto de Ley $\mathrm{N}^{\circ}$ 03602/2013-CR; con lo cual, ya no se discutiría si la indemnización justipreciada se encuentra afecta o no al Impuesto a la Renta, teniéndose en cuenta, que lo que se encontraría gravada sería la ganancia obtenida, no la indemnización justipreciada como tal. 


\section{REFERENCIAS}

Bravo Cucci, J. (2005). Algunas meditaciones sobre el Concepto de Renta. Revista Vectigalia. Tomo $N^{\circ} 1,41-45$.

Código Civil (Perú). Decreto Legislativo N 295. (25 de julio de 1984). Recuperado de: http://spij.minjus.gob.pe/normativa_basica3.html

Código Procesal Civil (Perú). Resolución Ministerial N 010-93-JUS. (22 de abril de

1993). Recuperado de: http://spij.minjus.gob.pe/normativa_basica3.html

Constitución Política del Perú. (1993). Recuperado de:

http://spij.minjus.gob.pe/CLP/contenidos.dll?f=templates\&fn=defaultconstitucion.htm\&vid=Ciclope:CLPdemo

De Trazegnies, F. (2 de julio de 2012). La razón de la sinrazón. El Comercio, p. A-13.

Decreto Legislativo $\mathrm{N}^{\circ}$ 1192. Decreto Legislativo que aprueba la Ley Marco de Adquisición y Expropiación de inmuebles, transferencia de inmuebles de propiedad del Estado, liberación de interferencias y dicta otras medidas para la ejecución de obras de infraestructura. (23 de agosto de 2015). Recuperado de: http://spij.minjus.gob.pe/

Decreto Supremo No 122-94-EF. Reglamento de la Ley del Impuesto a la Renta. (21 de septiembre de 1994). Recuperado de: http://spij.minjus.gob.pe/

Decreto Supremo N 86-2004-EF. Modifican el Reglamento de la Ley del Impuesto a la Renta. (04 de julio de 2004). Recuperado de: http://spij.minjus.gob.pe/

Dromi, J. R. (2005). Derecho Administrativo. Buenos Aires-Argentina: Gaceta Jurídica.

Fernández Cartagena, J. (2004). El Concepto de Renta en el Perú: Ámbito de Aplicación del Impuesto a la Renta. Revista IPDT (VIII Jornadas Nacionales de Derecho Tributario), 1-18. Recuperado de: http://www.ipdt.org/editor/docs/07_VIIIJorIPDT_JFC.pdf

García Mullín, J.R. (1978). Manual del Impuesto a la Renta (Doc. № 872). Buenos Aires: Organización de Estados Americanos, Centro Interamericano de Estudios Tributarios.

Garrido Falla, F. (2006). Tratado de Derecho Administrativo. Madrid: Tecnos.

Gutiérrez Camacho, W. (2010). Código Civil Comentado. Lima: Gaceta Jurídica. 
Informe $\mathrm{N}^{\circ}$ 0149-2015-SUNAT/5D0000 (16 de octubre de 2015). Superintendencia Nacional de Aduanas y de Administración Tributaria (SUNAT). Recuperado de : http://www.sunat.gob.pe/legislacion/oficios/2015/informe-oficios/i149-2015.pdf

Informe $\mathrm{N}^{\circ}$ 064-2006-SUNAT/2B0000 (13 de marzo de 2006). Superintendencia Nacional de Aduanas y de Administración Tributaria (SUNAT). Recuperado de: http://www.sunat.gob.pe/legislacion/oficios/2006/oficios/i0642006.htm

Informe $\mathrm{N}^{\circ}$ 0146-2015-SUNAT/5D0000 (12 de octubre de 2015). Superintendencia Nacional de Aduanas y de Administración Tributaria (SUNAT). Recuperado de: http://www.sunat.gob.pe/legislacion/oficios/2015/informe-oficios/i146-2015.pdf

Informe $\mathrm{N}^{\circ}$ 033-2014-SUNAT/5D0000 (14 de julio de 2014). Superintendencia Nacional de Aduanas y de Administración Tributaria (SUNAT). Recuperado de: http://www.sunat.gob.pe/legislacion/oficios/2014/informe-oficios/i033-20145D0000.pdf

Informe $N^{\circ}$ 91-2014-SUNAT/5D0000 (29 de octubre de 2014). Superintendencia Nacional de Aduanas y de Administración Tributaria (SUNAT). Recuperado de: http://www.sunat.gob.pe/legislacion/oficios/2014/informe-oficios/i0912014-5D0000.pdf

Informe $\mathrm{N}^{\circ}$ 142-2010-SUNAT/2B0000 (13 de octubre de 2010). Superintendencia Nacional de Aduanas y de Administración Tributaria (SUNAT). Recuperado de: http://www.sunat.gob.pe/legislacion/oficios/2010/informe-oficios/i1422010.pdf

Informe $N^{\circ} 314-2005-S U N A T / 2 B 0000$ (23 de diciembre de 2005). Superintendencia Nacional de Aduanas y de Administración Tributaria (SUNAT). Recuperado de: http://www.sunat.gob.pe/legislacion/oficios/2005/oficios/i3142005.htm

Ley $\mathrm{N}^{\circ} 30025$. Ley que facilita la adquisición, expropiación y posesión de bienes inmuebles para obras de infraestructura y declara de necesidad pública la adquisición o expropiación de bienes inmuebles afectados para la ejecución de diversas obras de infraestructura. (15 de mayo de 2013). Recuperado de: http://spij.minjus.gob.pe/

Ley $\mathrm{N}^{\circ} 27628$. Ley que facilita la ejecución de obras públicas viales. (8 de enero de 2002). Recuperado de: http://spij.minjus.gob.pe/

Medrano Cornejo, H. (2004). Ámbito de Aplicación del Impuesto a la Renta en el Perú. Revista IPDT (VIII Jornadas Nacionales de Derecho Tributario), 1-20.

Recuperado de: http://www.ipdt.org/editor/docs/01_VIIIJorIPDT_HMC.pdf

Medrano Cornejo, H. (12 de junio de 2013). El Impuesto a la Renta y la Nueva Ley de Expropiación. El Comercio, p. B-2.

Proyecto de Ley N ${ }^{\circ} 3026 / 2013-C R$. Proyecto de Ley que precisa la Tercera Disposición Final de la Ley $\mathrm{N}^{\circ}$ 27117. (4 de diciembre de 2013). En espera del Dictamen de 
la Comisión de Economía. Recuperado de:

http://www.congreso.gob.pe/proyectosdeley/

Proyecto de Ley $\mathrm{N}^{\circ} 3352 / 2013-\mathrm{CR}$. Ley que modifica el art. $15^{\circ}$ de la Ley $\mathrm{N}^{\circ}$ 27117. (4 de abril de 2014). En espera del Dictamen de la Comisión de Economía.

Recuperado de: http://www.congreso.gob.pe/proyectosdeley/

Proyecto de Ley N N $^{\circ} 602 / 2013-C R$. Proyecto de Ley de Inafectación del IR a la indemnización justipreciada pagada por el Estado en las expropiaciones. (12 de junio de 2014). En espera del Dictamen de la Comisión(es) de Economía, Banca, Finanzas e Inteligencia Financiera. Recuperado de: http://www.congreso.gob.pe/proyectosdeley/

Resolución del Tribunal Fiscal N 616-4-99 (de fecha 22 de junio de 1999) Tribunal Fiscal. Recuperado de:

http://www.mef.gob.pe/contenidos/tribu_fisc/Tribunal_Fiscal/PDFS/1999/4/199 9_4_0616.pdf

Resolución del Tribunal Fiscal N 00542-1-2007 (de fecha 23 de enero de 2007) (Lima). Tribunal Fiscal. Recuperado de: http://www.mef.gob.pe/contenidos/tribu_fisc/Tribunal_Fiscal/PDFS/2007/1/200 7_1_00542.pdf

Resolución del Tribunal Fiscal N 01930-5-2010 (fecha 23 de febrero de 2010). Tribunal Fiscal. Recuperado de :

http://www.mef.gob.pe/contenidos/tribu_fisc/Tribunal_Fiscal/PDFS/2010/5/201 $\underline{0 \_5 \text { 01930.pdf }}$

Ruiz de Castilla Ponce de León, F.J. (2010). Impuesto a la Renta: Aspectos Subjetivos (versión actualizada) [mensaje en un blog]. Recuperado de:

http://blog.pucp.edu.pe/blog/franciscoruiz/2010/12/13/impuesto-a-la-rentaaspectos-subjetivos-version-actualizada/

Sentencia del Tribunal Constitucional $N^{\circ}$ 00319-2013-PA/TC (Inaplicación del artículo 5 de la LIR [D.S. $\mathrm{N}^{\circ}$ 179-2004-EF] de fecha 18 de junio de 2013). Recuperado de: http://www.tc.gob.pe/jurisprudencia/2013/00319-2013-AA.pdf

Sentencia del Tribunal Constitucional N 05312-2009-PA/TC. Recuperado de: http://www.tc.gob.pe/jurisprudencia/2011/05312-2009-AA.pdf

Sentencia del Tribunal Constitucional N 05614-2007-PA/TC. Recuperado de: http://www.tc.gob.pe/jurisprudencia/2009/05614-2007-AA.pdf

Sentencia del Tribunal Constitucional N 0864-2009-PA/TC. Recuperado de: http://www.tc.gob.pe/jurisprudencia/2009/00864-2009-AA.pdf

Villanueva Gutiérrez, W. (2007). Las rentas de capital y ganancias de capital. Revista Jus. Doctrina \& Práctica. Lima-Perú. 
Zegarra Vílchez, J. y Zuzunaga del Pino, F. (2004). El Impuesto a la Renta sobre las Ganancias de Capital obtenidas en la Enajenación de Inmuebles. Revista IPDT (VIII Jornadas Nacionales de Derecho Tributario), 1-22. Recuperado de:

http://www.ipdt.org/editor/docs/13_VIIIJorIPDT_FZDP-JCZV.pdf 


\section{BIBLIOGRAFÍA}

Ataliba, G. (2011). Hipótesis de Incidencia Tributaria. Lima: Ara Editores.

Danos Ordóñez, J. (2006). El principio de constitucional de no confiscatoriedad de los tributos en la jurisprudencia del Tribunal Constitucional Peruano. Lima: Palestra Editores.

Durán Rojo, L. (2015). Impuesto a la Renta. Lima: AELE.

Gamba Valega, C. (2006). Capacidad Económica y Jurisprudencia del Tribunal Constitucional en Temas de Derecho Tributario y de Derecho Público. Libro Homenaje a Armando Zolezzi Möller. Lima-Perú: Palestra Editores.

García Chavarri, A. (2011). Algunas anotaciones sobre el derecho de propiedad desde la reciente jurisprudencia del Tribunal Constitucional sobre la materia. Revista: Gaceta Constitucional. Tomo $N^{\circ} 43$. Lima-Perú.

Landa Arroyo, C. (2006). Los principios tributarios en la Constitución de 1993. Una perspectiva constitucional. Lima: Palestra Editores.

Miranda \& Amado Abogados (2015). Inconstitucionalidad del Impuesto a la Renta en las expropiaciones: historia de un proceso de amparo. Lima: Miranda \& Amado Abogados.

Sentencia del Tribunal TC N 004-2004-AI/TC. Recuperado del sitio de internet del Tribunal Constitucional del Perú (TC):

http://www.tc.gob.pe/jurisprudencia/2004/00004-2004-AI\%2000011-2004AI\%2000012-2004-AI\%2000013-2004-AI\%2000014-2004-AI\%2000015-2004AI\%2000016-2004-AI\%2000027-2004-AI.html

Sentencia del Tribunal Constitucional N 0031-2004-AI/TC. Recuperado de: http://www.tc.gob.pe/jurisprudencia/2005/00031-2004-AI.html

Sentencia del Tribunal Constitucional N ${ }^{\circ}$ 5221-2006-AA/TC. Recuperado de: http://www.tc.gob.pe/jurisprudencia/2007/05221-2006-AA.pdf

Sentencia del Tribunal Constitucional N ${ }^{\circ}$ 7364-2006-PA/TC. Recuperado de: http://www.tc.gob.pe/jurisprudencia/2008/07364-2006-AA.pdf

Sentencia del Tribunal Constitucional N 3258-2010-PA/TC. Recuperado de: http://www.tc.gob.pe/jurisprudencia/2011/03258-2010-AA.pdf

Simons Pino, A. (7 de marzo de 2012). Te expropio y además te confisco, con arreglo a Ley. Gestión, p. 8. 